Illinois State University

ISU ReD: Research and eData

Theses and Dissertations

10-16-2017

\title{
Culturally Responsive Educational Leadership: A Qualitative Study of Indigenous Innovations
}

Bert Klunder

Illinois State University, baklund@ilstu.edu

Follow this and additional works at: https://ir.library.illinoisstate.edu/etd

Part of the Higher Education Administration Commons

\section{Recommended Citation}

Klunder, Bert, "Culturally Responsive Educational Leadership: A Qualitative Study of Indigenous Innovations" (2017). Theses and Dissertations. 791.

https://ir.library.illinoisstate.edu/etd/791

This Dissertation is brought to you for free and open access by ISU ReD: Research and eData. It has been accepted for inclusion in Theses and Dissertations by an authorized administrator of ISU ReD: Research and eData. For more information, please contact ISUReD@ilstu.edu. 


\title{
CULTURALLY RESPONSIVE EDUCATIONAL LEADERSHIP:
}

\section{A QUALITATIVE STUDY OF INDIGENOUS}

\author{
INNOVATIONS
}

\author{
Bert Klunder
}

\section{Pages}

This qualitative study of culturally responsive educational leadership (CREL) explores noteworthy cases of system-wide innovation spanning decades through interviews with seven education professionals active within Indigenous movements and organizations driving Native Hawaiian education and the revitalization of Hawaiian language and culture. The research focus includes the Na Honua Mauli Ola Guidelines (and Pathways) for Culturally Healthy and Responsive Learning Environments, along with the preceding Kumu Honua Mauli Ola Philosophy Statement. Interviewees, all with direct connections to these innovations, illuminate their local and global significance through personal accounts of their development and implementation. The study's uniquely situated methodology yields rich data for systems-level analysis of these innovative cases of CREL and related work addressing persistent inequities for historically underserved students in the singularly unique environment, education system and sociocultural context of Hawai'i. A transformative leadership centered theoretical framework guides data analyses striving for a more complete process-oriented understanding, organizationally and operationally, of effective system-wide CREL practice (across all levels of the P-20 
continuum and among various organizational types) in an uncommonly diverse community, as demonstrated in these cases of Indigenous innovation exemplifying CREL in Hawai'i.

KEYWORDS: Education; Leadership; Culturally Responsive; Hawaiian; Indigenous;

Transformative 
CULTURALLY RESPONSIVE EDUCATIONAL LEADERSHIP:

A QUALITATIVE STUDY OF INDIGENOUS

INNOVATIONS

BERT KLUNDER

A Dissertation Submitted in Partial

Fulfillment of the Requirements

for the Degree of

DOCTOR OF PHILOSOPHY

Department of Educational Administration and Foundations

ILLINOIS STATE UNIVERSITY 
Copyright 2017 Bert Klunder 


\section{CULTURALLY RESPONSIVE EDUCATIONAL LEADERSHIP:}

A QUALITATIVE STUDY OF INDIGENOUS

INNOVATIONS

BERT KLUNDER

COMMITTEE MEMBERS:

Mohamed Nur-Awaleh, Chair

Lydia Kyei-Blankson

Diane Renn

Lucille Eckrich 


\section{ACKNOWLEDGMENTS}

This research would not be possible without the support of several organizations, including the Native Hawaiian Education Council, the Ka Haka 'Ula O Ke'elikolani College of Hawaiian Language at the University of Hawai'i-Hilo, 'Aha Punana Leo, Inc. and Kanu o Ka 'Aina Learning 'Ohana. I am truly honored to know all of the incredible people I had the privilege of working with in this research effort, including Keiki Kawai’ae‘a, Ka‘iulani Pahio, Paula De Morales, Namaka Rawlins, Pila Wilson, Kanoe Kanaka'ole, Cathy Arnold, Luana Jones, Collin Kippen, Erika Vincent, Sylvia Hussey, Walter Kahumoku and many others across the Hawaiian Islands who provided assistance, encouragement and their blessings.

Special thanks to my Faculty Committee for their support and guidance, and to the Educational Administration and Foundations Program at Illinois State University, including the faculty, students and professional colleagues I had the pleasure of working with throughout my doctoral study journey.

Much love to my parents and extended family for their spirited encouragement.

Words cannot express my gratitude for the inspiration and endless support of my wife, who stuck with me through the toughest times and gave me the strength to follow my heart. Love you Bea.

B. K. 


\section{CONTENTS}

\section{Page}

ACKNOWLEDGMENTS

CONTENTS

TABLES

iv

FIGURES

v

CHAPTER

$\begin{array}{ll}\text { I. THE PROBLEM AND ITS BACKGROUND } & 1\end{array}$

Introduction 1

Background and Context 4

The Native Hawaiian Education Act 6

NHEA Reauthorization and Looming Shifts $\quad 8$

The Na Honua Mauli Ola Guidelines $\quad 8$

$\begin{array}{ll}\text { Statement of the Problem } & 10\end{array}$

$\begin{array}{ll}\text { Statement of Purpose } & 11\end{array}$

Research Questions $\quad 12$

Significance of the Study 12

Limitations of the Study $\quad 15$

$\begin{array}{ll}\text { Definition of Terms } & 16\end{array}$

\begin{tabular}{ll} 
II. & REVIEW OF RELATED LITERATURE \\
\hline
\end{tabular}

$\begin{array}{ll}\text { Organizational Theory and Research } & 18\end{array}$

$\begin{array}{ll}\text { Culturally Responsive Educational Leadership } & 21\end{array}$

Postmodern Shifts Across Domains $\quad 29$

Indigenous Theory and Research 32

Summary: Leadership Revisited $\quad 40$

Theoretical Frameworks 41 
III. RESEARCH DESIGN AND METHODOLOGY

Participants in the Study $\quad 50$

Data Collection $\quad 54$

Analysis $\quad 57$

$\begin{array}{lll}\text { IV. } & \text { FINDINGS } & 60\end{array}$

V. DISCUSSION, CONCLUSIONS, IMPLICATIONS AND RECOMMENDATIONS FOR FUTURE RESEARCH 85

Discussion $\quad 85$

$\begin{array}{ll}\text { Conclusions } & 91\end{array}$

Implications $\quad 93$

Recommendations for Future Research 95

$\begin{array}{lc}\text { REFERENCES } & 98\end{array}$

APPENDIX A: $\quad$ Letter of Recruitment 111

APPENDIX B: Letter of Consent 113

$\begin{array}{lll}\text { APPENDIX C: } & \text { Participant Survey } & 115\end{array}$

APPENDIX D: $\quad$ Participant Accounts of Relevant Experiences $\quad 119$

$\begin{array}{lll}\text { APPENDIX E: } & \text { Semi-Structured Interview Questions } & 120\end{array}$ 


\section{TABLES}

Table

Page

1. Professional Profile of Study Participants 


\section{FIGURES}

Figure $\quad$ Page

1. Application of Theoretical Framework 
CHAPTER I

\section{THE PROBLEM AND ITS BACKGROUND}

Introduction

Hawai' $i$ is an awe-inspiring circumstance for conducting in-depth studies of educational leadership strategies, methods and best practices effectively addressing persistent inequities and supporting historically underserved students in the American system. On this remote and isolated island chain in the middle of the Pacific, a wide variety of complex issues and problems exacerbate educational disparities, particularly for Indigenous students. To address these difficult conditions, movements in Native Hawaiian education have enabled a wide range of targeted efforts and the localized development of numerous solutions over decades, including noteworthy innovations representing exemplary articulations and manifestations of culturally responsive educational leadership (CREL).

This research project uses a case study approach to examine - through qualitative analyses conducted from the researcher's non-Indigenous perspective - the evolution and impact of specific Indigenous innovations exemplifying CREL in Hawai'i, based on data and interview testimony obtained directly from education professionals who participated in their creation and implementation. Beyond collecting first-hand accounts of innovative CREL processes and their products, this study will also explore their local and global significance through analyses of their development and resultant influence in the singularly unique Hawaiian education system and context. The processes examined in this research include those 
undertaken by special coalition groups that convened to create specific products guiding Native Hawaiian education efforts. These groups, representing the cases targeted in this study, include partner organizations and committees involving educational leaders from a variety of institutions, agencies and other collectives active in Native Hawaiian education efforts across all levels of the P-20 continuum. The noteworthy products resulting from the system-wide collaborations examined in this research include the first and second editions of the Na Honua Mauli Ola (NHMO) Hawai'i Guidelines for Culturally Healthy and Responsive Learning Environments (Native Hawaiian Education Council, 2002; 2015).

A core partner organization in efforts yielding the NHMO Guidelines is the Native Hawaiian Education Council (NHEC), which was created through the implementation of the Native Hawaiian Education Act (NHEA) - this legislation, originally enacted by the U.S. Congress in 1988, represents significant overarching policy related to this study. Another core partner in these efforts is the Ka Haka 'Ula O Ke'elikōlani College of Hawaiian Language (CHL) established by the Hawai'i State Legislature in 1997 at the University of Hawai'i at Hilo (UHH). The UHH$\mathrm{CHL}$ was also a core partner in the development of the Kumu Honua Mauli Ola (KHMO) Philosophy Statement ('Aha Punana Leo, Inc. and Ke Haka 'Ula O Ke'elikolani, 2009) - originally created in 1998 in Hawaiian Language and later translated into multiple languages in 2009 which greatly influenced the development of the NHMO Guidelines (and, therefore, is another key product focused on in this research). Geographically, this study is focused mainly on the county and school district of the "Big Island" of Hawai' $i$, which is home to the UHH-CHL and other partner organizations engaged in these CREL efforts. 
In order to understand more completely, from a non-Indigenous perspective, how certain innovative Indigenous processes and products have aided the progress of the Native Hawaiian education movement as a whole, this qualitative study seeks to identify significant aspects, salient features, and core elements of CREL represented in participant accounts of the evolution and impact of these innovations. The system-wide efforts yielding the $\mathrm{KHMO}$ Philosophy Statement and subsequent NHMO Guidelines and Pathways are appropriate entry points for exploring the wider Native Hawaiian education movement in a global context, because these processes and products represent unique syntheses of epistemological, theoretical and practical foundations developed locally and adapted from other Indigenous contexts abroad. These Native Hawaiian innovations are also widely adaptable and can offer meaningful insight and guidance for CREL efforts elsewhere in the world. This case study will incorporate a combination of research methods and draw from multiple domains of relevant theory and prior inquiry in order to achieve an authentic, representative and situated understanding of CREL in this unique circumstance.

In this research, CREL is approached as a collective undertaking spanning education levels, organizational domains and stakeholder realms; in this way, leadership is considered in terms of the shared responsibility and combined influence of all stakeholders involved, rather than solely as the purview of individuals in official positions of authority. Using a systems-level scope, the process-oriented inquiry and analyses conducted in this study speak to administrative vantage points within and across institutions, districts and regions; bearing in mind that the concerns of all stakeholders are integral to CREL, administrators are the target 
audience for this research. The postsecondary arena is of particular interest in this study, specifically in terms of its potential to drive meaningful system-wide change and to guide the evolution of social justice focused leadership strategies and methods across systems. A core purpose of this research is to make meaningful contributions to evolving CREL discourse through documentation and analyses of participants' stories of significant Indigenous innovations, their influence and related implications within and beyond the unique education system and context of Hawai'i.

\section{Background and Context}

Hawai'i has many unique characteristics, including its designations as the $50^{\text {th }}$ state (since 1959) and the only island state in the nation. Many persistent issues, regrettable conditions and formidable challenges have illustrated the influence of what Meller (1992) describes as the "institutionalized centralization" of political power through the formal structure of constitutional government that "is the most centralized and its administration the most integrated of all fifty states in the union, a distinction with long historical antecedents" (Meller, 1992, p. 13). Over the course of two centuries post-monarchy - throughout the rise and fall of the short-lived Hawaiian Republic and subsequent periods as a U.S. territory and state - Western influence has driven an uncommon evolution of centralized bureaucratization and concentrated executive power in Hawai'i's public sector. The trend of structural centralization extends across their entire education system, and the singularly unique 
characteristics of this system have demanded unique approaches toward addressing key challenges concerning Indigenous students specifically.

Beyond being the only state with a single centralized public school system - an issue that Bean and Zulich (1992) describe as being at the heart of a gradually evolving education reform movement on these islands - Hawai'i is also the only state that is not dependent on local property taxes as a major revenue source for funding its public education system, which depends predominantly on state and federal funding sources (State of Hawai'i Department of Education, 2010, p. 13). Statewide, the growing percentage of students with at least one special need has represented a true majority for years, totaling approximately 55\% in 2010 (State of Hawaii Department of Education, 2010, p. 12) and totaling approximately 59\% in 2015 (State of Hawaii Department of Education, 2015, p. 1). Rates of economically disadvantaged students have increased significantly in the past decade, and some areas with the highest rates of poverty and students with special needs are in the largely rural county and school district of the Big Island of Hawai' $\mathrm{i}$ - identified during the 2000 U.S. Census as the most ethnically diverse county in America (Office of Hawaiian Affairs, 2006) - where this study is situated.

Among numerous contextual considerations related to unique elements, factors and problems faced by the Native Hawaiian education movement, the needs of language and culture preservation and revitalization are paramount, due to a long history of Western influence, colonialism and domination severely endangering Hawaiian culture (Meller, 1992). The loss of sovereignty, the loss of most of their former numbers, the near extinction of their native language, and the loss of countless resources over time created urgent needs for Native 
Hawaiians that eventually were acknowledged formally in federal policy, including pivotal NHEA legislation. This Act signified a fundamental shift in relations between Native Hawaiians and the United States government and, consequently, involved a number of complex leadership challenges in its implementation.

\section{The Native Hawaiian Education Act}

The NHEA, last updated in 2008 (at the time of this study), was originally enacted by the U.S. Congress in 1988 and last reauthorized in 2002 as a part of the No Child Left Behind Act (NCLB), "to develop innovative educational programs to assist Native Hawaiians by providing grant funds for Native Hawaiian educational activities and fostering community participation in strategies for improvement" (Government Accountability Office, 2008, p. 8). The NHEA authorized the U.S. Department of Education (DOE) to offer competitive grant awards (in recent years, over $\$ 30$ million annually, but declining), establish and fund a statewide Native Hawaiian Education Council (NHEC), and facilitate the development of local island education councils to carry out the purposes of the Act. According to Benham and Heck (1998), the NHEA was one of several outcomes reflecting a shift in federal policy development that enabled greater access to various programs, services and benefits by Indigenous groups. They explain:

The Native Hawaiian Education Act specifically extends equal privileges and rights afforded other Native Americans under other acts... What is of further interest about this act is that it chronicles the role of the United States government and U.S. citizens in undermining Hawaiian sovereignty (which was recognized by the United States between 1826 and 1893) at the time of the 1893 overthrow of the government. Moreover, it acknowledges the special responsibility of Congress toward Native Hawaiians because of those illegal actions. It is because of this Act that Native Hawaiian groups argue that they have a right to full self-determination under international law - similar to other 
groups that were colonized in the 1800 s and subsequently given full rights of selfdetermination. (Benham and Heck, 1998, pp. 219-220)

Through a series of policy developments dating back to the Civil Rights Act of 1964, and including the Bilingual Education Act of 1968, the Indian Civil Rights Act of 1968 and the Community Services Act of 1974, the Native Hawaiian relationship with the U.S. government has been defined gradually and incrementally over decades in connection with the same legal definition processes for other Indigenous populations in the U.S., as noted by Benham and Heck (1998). They explain that, "much of the present politicization of Hawaiian educational issues is focused on the long-term survival of the Hawaiian Language" (p. 195), and much of the NHEA investment from DOE supports localized language-based, culture-based education programs.

The NHEA makes several significant statements regarding the history of relations between Native Hawaiians and the federal government. Political and legislative events recounted in the NHEA provide evidence of the government's official recognition of the so-called "unique status" of Indigenous Hawaiians, their "never relinquished" sovereign condition, and rights to selfdetermination and self-governance (U.S. Congress, 2008). This is demonstrated in part through charting their inclusion in a series of other legislative acts that redefined the relationship between the federal government and other Indigenous Peoples, including the Native American Programs Act of 1974. Also highlighted in the NHEA are congressional efforts to address persistent problems over a timeline stretching more than a century (U.S. Congress, 2008). The NHEA represents a compilation of acts and resolutions serving in part as a formal declaration of changing relations with (and respectful recognition of) Native Hawaiians. It also serves in large 
part as justification for providing access to benefits, services and programs - including federally funded grant programs for Native Hawaiian education efforts of all kinds that are locally coordinated in their implementation, while being overseen and supported by the NHEC.

\section{NHEA Reauthorization and Looming Shifts}

During the time of this study, the pending reauthorization of the Elementary and Secondary Education Act (ESEA), and the NHEA (ESEA Title VII), signaled potential changes to the NHEC and the corresponding grant program system. Later versions of the ESEA at this time (as outlined in Title VII), would result in the restructuring of the NHEC, including replacing the role of Island Councils with appointed district representatives (U.S. Congress, 2011a). Other anticipated changes resulting from the reauthorization process included reduced funding for the grant program, along with potential restructuring of the NHEC statewide council and administrative organization, according to Council members (personal communication, 2012). In the uncertain political climate of this period, the ESEA reauthorization process could, at the very least, yield significant reductions in the variety, reach and impact of NHEA grant activities and, potentially, threaten the very existence of the NHEA, along with the NHEC organization and grant program system tied to this legislation.

\section{The Na Honua Mauli Ola Guidelines}

In 2002, the NHEC, in partnership with the UHH-CHL, developed and adopted the NHMO Guidelines (NHEC, 2002), which were adapted from and built upon a template from the 
previously created Alaska Standards for Culturally Responsive Schools (1998) through a partnership with the Alaska Native Knowledge Network (NHEC, 2002, p. 4). The epistemological foundations for these guidelines were developed with the help of scholars from the UHH-CHL including the KHMO Philosophy Statement (Kawai'ae'a \& Wilson, 2007) - and the NHEC ensured the alignment of these guidelines with NHEA legislative mandates. In the words of Colin Kippen, former Executive Director of the NHEC, these guidelines provided "a framework for language-based, place-based and culture-based education" that was more appropriately aligned with the NHEA itself, with the consensus view of the NHEC and local education councils, and with the unique circumstances of the corresponding grant program (personal communication, 2009).

Key leadership challenges faced by the NHEC in their administration of the NHEA grant program system have involved a number of complex issues and tensions connected with educational policy. For example, the unique structure and character of the Hawaiian education system in comparison with other U.S. states made the process of adhering to NCLB mandates troublesome, as revealed by data published in the State Superintendent's Annual Reports (State of Hawaii Department of Education, 2008, 2009, 2010, 2015) and other educational studies conducted in the Pacific Region (Ryan \& Scott, 2008; Burger, Mauricio \& Ryan, 2007). The development and later updating of the NHMO Guidelines signify ongoing attempts to more effectively address significant issues, obstacles and tensions embedded in the history of Native Hawaiian education outcomes, in part through providing a new framework and foundation for understanding the Hawaiian cultural context and worldview in relation to the non-Indigenous 
Western education system. Evolving efforts like these within the Native Hawaiian education movement have fueled numerous efforts in the expansion of Hawaiian language instruction options, multicultural curricula and other recent adaptations in educational practice in Hawai' $\mathrm{i}$ aimed at improving historic disparities and inequitable conditions for Indigenous students through encouraging the preservation and revitalization of Hawaiian language and culture.

\section{Statement of the Problem}

Throughout America and abroad, educational leaders face endless challenges in their attempts to support the success of Indigenous students through the development of policies, programs and systems that can enable culturally responsive educational practices. The singularly unique context and history of the Native Hawaiian education movement reflects the exacerbated issues and problems faced by this unique population of Indigenous students and the professionals that serve them. These problems include higher rates of special needs and poverty among Native Hawaiian students, a range of difficulties encountered in the development of policies (nationally and locally) to improve the conditions of their unique situation, limited resources and funding for preventive measures and interventions, and challenges connected with the coordination, implementation and documentation of programs aimed at improving education outcomes for Indigenous students. This study focuses on system-wide efforts undertaken by special coalitions of educational leaders to address the unique issues and inequities faced by Native Hawaiian students in a localized manner that is culturally aligned and responsive to their needs. 


\section{Statement of Purpose}

This study has three main goals. The first is to achieve, through qualitative analyses conducted from the researcher's Western white male standpoint, a representative understanding (in conceptual and practical terms) of key articulations and manifestations of CREL within the Native Hawaiian education movement, according to education professionals who helped create and implement key innovations exemplifying CREL. The second goal is to draw wider attention to lesser known aspects and outcomes of the Native Hawaiian education movement and its singularly unique context through identifying key elements, factors and forces related to CREL in this particular situation. The third goal is to demonstrate the global significance of these CREL innovations in relation to resonant efforts in the American system and abroad attempting to address similar issues and inequities for unique student populations that are often identified as disadvantaged, underserved and underrepresented.

An objective related to the first goal of this qualitative study is to complete thorough analyses of related documents and interview data collected from participants in the Native Hawaiian education movement (primarily, the writers, researchers and members of partner organizations that developed both editions of the NHMO Guidelines and the preceding KHMO Philosophy Statement) in order to achieve an appropriately situated understanding of CREL in this context. An objective related to the second goal is to, through the analysis process and with the aid of study participants, determine key information (related to CREL in this context and the evolution of the movement) that merits highlighting, translation and further explanation for outsiders with little reference to this unique situation. An objective related to 
the third goal of this study is to draw relevant parallels and connections with other resonant movements (and targeted efforts to address similar issues for unique student groups) in order to promote clearer understanding of the relevance and adaptability of locally developed CREL innovations elsewhere in the American system and abroad.

\section{Research Questions}

Questions addressed in this research include (but are not limited to) the following:

- What is essential to understand about CREL in the unique context of Hawai $i$, according to participants in this study?

- How are selected cases of Native Hawaiian innovations exemplifying CREL in this study significant in a global context?

- In this case study of Native Hawaiian innovations, what significant implications are apparent in relation to CREL efforts and resonant movements elsewhere in the world?

\section{Significance of the Study}

The timing of this study coincides with an important period of transition for the Native Hawaiian education movement, due to the uncertain fate of the NHEA through ESEA (Title VII) reauthorization. The innovations examined in this research signify substantial progress for the movement and reflect a strong core foundation developed locally through generations of collaboration and perseverance. This study is also concerned with troubled history surrounding the movement, the uncertain future related to pending legislation, and persistent issues that remain unresolved for Native Hawaiian communities. In addition to promoting wider awareness of noteworthy achievements and innovations driven by the movement, this study 
builds on existing educational research by applying a uniquely situated systems-level approach toward the study of conceptualizations, strategies and methods of CREL across the P-20 continuum, and this approach is particularly relevant to the work of educational administration at all levels. This qualitative study also contributes further to emerging discourse among all stakeholders concerning educational leadership that is collectively realized and manifested, culturally aligned, and contextually appropriate for uniquely diverse constituencies and communities of service.

Riehl, Larson, Short and Reitzug (2000) argue that, "a new appreciation for the knowledge of administrative practitioners [in education] needs to emerge" (p. 395), due to lingering disagreements between two communities of practice represented within the field of educational administration with respect to their 'knowledge work' - those being conventional theoretical research and practical research - and the authors suggest that they should strive to become one community of scholars. They assert that, "conventional research stands only to benefit from the fertile ground of emerging methods, some of which come from the realm of practical research" (p. 398), and recommend an integrated view of research in educational administration (specifically in the context of doctoral programs) that is characterized by three dimensions (the who, the why and the how) of research. Their suggestions concerning the value of practical scholarship and their call to re-conceptualize research in educational administration is directly relevant to this study - which seeks to develop an appropriately integrated approach toward the study of CREL, including conventional methods and the 
incorporation of reflective practice (Schon, 1982), "theories-in-use" (Argyris \& Schon, 1974) and other practical methods that suit meaningful participant engagement and observation.

Multiple gaps in existing literature are addressed in this study of CREL through the unique application of theoretical foundations from transformative leadership literature and the unique combination of qualitative data collection methods enabling rich data to be documented. This study is concerned with facilitating wider awareness and clearer understandings of the CREL innovations that are the focus of this research, while encouraging deeper appreciation of how comprehensive systems-level leadership perspectives, strategies and process models can aid collective efforts to address systemic issues, persistent inequities and complex problems represented across the educational continuum. As a documentarian and researcher encouraging meaningful CREL discourse and action, I aim to support the evolution of the efforts studied here (and the continuing progress of the wider Native Hawaiian education movement) through the work of this project. The interview content documented here, albeit a small sampling of voices from the movement, speaks broadly and deeply to the complex topic of CREL and the core research questions of this study. Accordingly, the methodological approach of this research is intended to facilitate drawing parallels, making connections and building bridges among multiple disciplines and domains of theory and practice related to CREL, while promoting awareness of exemplary Native Hawaiian innovations and their global significance. 


\section{Limitations of the Study}

The most notable limitation of this study, given its Indigenous central focus, is that it is conducted from the researcher's non-Indigenous vantage point. Since I have no Hawaiian ancestry, nor Hawaiian language fluency, nor complete working knowledge of Hawaiian cultural traditions and protocol, I cannot claim to fully comprehend many of the concepts, practices and related cultural meanings of Indigenous articulations and manifestations of CREL to the extent that a Native Hawaiian researcher would be capable of achieving. Due to my organizational and operational focus, I am also utilizing primarily Western theoretical frameworks in the analysis process, rather than mainly Indigenous theoretical frameworks and techniques, due to my own Western-oriented standpoint and unique intentions. Indigenous research and theory will be incorporated in the analysis process for the sake of appropriately expanding the scope of inquiry beyond the reach of conventional Western parameters, and these analyses will be conducted accordingly with careful consideration of non-Western interpretations of key concepts to the best of my ability.

Despite these limitations, my unique roles throughout this study as an engaged resident of East Hawai'i (with professional experience in the Hawaiian education system and among a range of public organizations serving Hawaiian communities over five years) enable a more situated stakeholder's perspective in the analysis process and facilitate a more representative understanding of local references and language used in interviews, as confirmed through member-checking and follow-up consultations with participants. To clarify, my approach to this research as a cultural outsider is intentional, in an effort to suit Western-oriented analysis 
processes - while encouraging and showing utmost respect for research not attempted in this particular study that is more appropriately conducted by Indigenous researchers - and also to actively demonstrate the value of conducting this type of reflexive cross-cultural research from a Westerner's perspective, despite its limits. The potential for this approach to yield significant contributions to the global research community and to encourage broader and deeper understandings of CREL in Indigenous contexts among Western researchers and education professionals is part of the impetus and justification for this unique study, which I feel truly honored and very blessed to conduct.

\section{Definition of Terms}

This study considers multiple definitions of CREL, and core elements of this topic are explored in the literature review that follows. The term innovation is used as a descriptor for CREL products and processes representing new articulations of old knowledge and new vehicles for preservation in the work of cultural revitalization; "innovation" is used in reference to the new and original aspects of these creations, though it is admittedly a limited descriptor that doesn't convey the nature of these cases completely. Similarly, the term movement, albeit limited, is used to describe social movements driving Native Hawaiian education; although the singular word "movement" is sometimes used, implying one movement, it is referring to a combination of movements driving Native Hawaiian education through Hawaiian language and culture revitalization. The term system-wide is used most often in reference to the statewide Hawaiian education system this study is concerned with, though there are also times when it is 
used generally as a qualifier of larger scale contexts for CREL efforts - for example, a state, a region, or nationally - that are beyond local. Systems-level is a term used to describe the scope of this study, which considers the system-wide landscape of Hawai'i within national and global contexts, thereby meriting the consideration of all educational levels, organizational types and stakeholder groups in this CREL research. 


\section{CHAPTER II}

\section{REVIEW OF RELATED LITERATURE}

Literature searches were conducted through institutional networks accessible as a student and employee in Illinois and Hawai'i during the course of this study. In Illinois, the databases of Milner Library at Illinois State University (including ERIC, EBSCO, etc.) and the IShare statewide network of libraries were utilized. In Hawai'i, the University of Hawai'i statewide library system was accessed through the Mookini Library on the UH-Hilo campus, and the statewide public library system was also utilized. Additionally, Google Scholar was used for supplemental literature searches.

\section{Organizational Theory and Research}

Understanding the nature of administration and leadership in any context involves the careful consideration of multiple realities invariably at work in any organization, according to Bolman and Deal (2008), who offer a meta-framework for analyzing organizations in terms of four primary dimensions (structural, human resources, political and symbolic). Their conclusions echo a growing chorus of scholars in recent decades from the domain of organizational theory and research calling for deeper comprehension of conceptual and functional differences between management and leadership, along with careful consideration of intangible elements in the study of organizations as living systems (Senge, 2006; Wheatley, 2000). In their compendium of organizational theory and research focusing on the intricacies of management and leadership, Bolman and Deal (2008) recount the evolution of prevailing 
popular thought in this domain and explain organizational behavior through their exploration of structural, human resource, political and symbolic "frames" of understanding represented in over a century of organizational studies. This meta-framework offers a practical means for analyzing general leadership issues and concerns in context, and additional contributions from the domain of organizational theory are also suited for the analysis of educational leadership contexts specifically.

The extensive analysis of Rost (1991) charts the evolution of research concerning management and leadership - terms no longer used interchangeably, as they once were among researchers until later in the twentieth century. Rost identifies post-industrial shifts in organizational research yielding new conceptualizations of management and leadership across disciplines and professional domains in all sectors - and his claims concerning the centrality of ethics in the practice of leadership are echoed by Greenleaf (2002) in his explanation of "servant leadership" as an ideal approach that incorporates a "first among equals" relational principle. Drath (2001) also acknowledges a paradigm shift toward relational understandings of leadership and late twentieth century trends that reflect a departure from traditional traitbased theories of leadership focused on individual contexts in search of more collectively oriented perspectives facilitating deeper examination of enigmatic leadership concepts.

Prevailing theories concerning leadership and organizational life that took hold early in the twentieth century - including those guided by efficiency-centered ideals of scientific management (Taylor, 1911) and rational bureaucracy (Weber, 1947), among others - have gradually given way to new ways of thinking about the complexities of leadership theory and 
practice. For example, Heifetz (1998) challenges long-standing assumptions through his portrayal of leadership as "adaptive work" (that can be successfully carried out with or without authority), and demonstrates adaptive leadership (Heifetz, Grashow, \& Linsky, 2009) through systems-oriented approaches toward diagnosing and addressing technical problems and adaptive challenges. Similarly, Wheatley (2000) calls for embracing the complexity and chaos of leadership practice through greater awareness of "new science" and changing postmodern worldviews. Other influential voices in the growing chorus of researchers signaling ongoing shifts in leadership theory and practice include Drucker (2001), who influenced transformations in the discipline of management science through his concept of "knowledge work" and Senge (2006), who helped embed the naturalistic mode of systems thinking in the discourse of organizational researchers, while promoting the concept of the "learning organization" signifying the relevance of understanding leadership as a shared and ultimately collective endeavor, rather than merely as solo missions for individuals in leadership positions.

The theoretical framework of organizational culture offered by Schein (2004) also provides relevant conceptual language for analyzing the collaborative work of leadership. Schein identifies the central challenges of internal integration and external adaptation in the process of leadership, while recognizing that, "leadership and culture are two sides of the same coin" (p. 1). His focus on the tacit assumptions shared among members of organizational groups as an influential force in organizations highlights the importance of informal communication and the socialization process among organizational members. 
This brief review of highlights from the domain of organizational theory and research speaking to the process of understanding the nature of leadership offers insight and guidance for understanding nearly any organizational circumstance. For education professionals in unique contexts, recognizing the alignment and convergence of perspectives from organizational and educational domains of leadership-focused literature encourages deeper understanding of important elements, factors and phenomena relevant to the topic of CREL. Through the following review of selected literature from the domain of educational theory and research, the concept of CREL will be explored and parallels across domains of related research will be identified, including relevant literature representing Indigenous perspectives.

\section{Culturally Responsive Educational Leadership}

In their review of literature related to culturally responsive schooling for Indigenous youth, Castagno and Brayboy (2008) acknowledge the difficulties in broadly defining culturally responsive schooling, because, "this literature is somewhat inconsistent with respect to the name given to these culturally based educational practices," which are commonly labeled "culturally responsive, culturally relevant, culture-based, and multicultural education" (p. 946). In this article and related literature explored below, much of which draws from studies pertaining to P-12 contexts, authors repeatedly acknowledge the range of interpretations present concerning key concepts, and Castagno and Brayboy (2008) add that, "the abundance of this work makes it difficult for most educators to access and make sense of this topic" ( $p$. 942). Bearing in mind the complexities of CREL as a conceptual focus, multiple theoretical 
perspectives are involved here for the sake of considering unique dimensions and meanings of CREL from different vantage points with respect to underrepresented students and concerning Indigenous contexts in particular.

Noteworthy research efforts in culturally responsive practices related to school leadership include studies of urban school principals conducted by Brown $(2004,2006)$ and Johnson $(2006,2007)$ that reference the concept of culturally relevant pedagogy defined by Ladson-Billings (1994) - who later reframed the "achievement gap" notion in terms of "education debt" (Ladson-Billings, 2006) with respect to students of color. The work of Villegas and Lucas (2002), including their model of culturally responsive teaching, is another example of research cited in a large body of literature focused on instructional practice that has informed and guided other less prevalent educational leadership focused studies. Following observations from Ladson-Billings (1995) regarding pedagogy, Johnson (2007) explains:

In sum, most approaches to culturally relevant or culturally responsive instruction described in the multicultural education literature not only utilize students' culture as a vehicle for learning, but also teach students how to develop a broader socio-political consciousness that enables them to critique the cultural norms, values, mores, and institutions that produce and maintain social inequities... Surprisingly, there have been few attempts to apply this culturally responsive framework to the study of leadership practice in high-poverty, challenging schools... Two aspects of 'culturally responsive leadership' that have received little attention in previous case studies are detailed descriptions of how school leaders have incorporated the history, values and cultural knowledge of students' home communities in the school curriculum and worked to develop a critical consciousness among both students and faculty to challenge inequities in the larger society. (2007, pp. 50-51)

Administratively focused research in cultural competence has yielded institutional culture assessments (Bustamante, Nelson \& Onwuegbuzie, 2009), cultural climate studies and other evaluative methods centered on appreciating and enabling institutional diversity. In a 
similar vein, Auerbach (2009) highlights the role of family and community engagement in her study of administrators who follow a proactive community-oriented approach toward urban school leadership. A considerable amount of educational leadership studies are approached using critical perspectives and focus on issues of social justice and equity - including Brown (2004, 2006), who integrates adult learning theory, transformative learning theory and critical social theory in her studies of leadership preparation program participants. Related literature also highlights the impact of colonialism (Spring, 2006), globalization (Burbules \& Torres, 2000) and various forms of oppression (Freire, 2000) with respect to students of color, and often recommends the incorporation of philosophy and pedagogy that are multicultural (Nieto, 2004), democratic (Dewey, 1916) and libratory (Freire, 2000) in efforts to adequately serve the unique needs of these historically underserved student populations.

In her review of literature related to the principal's role in creating inclusive schools for diverse students, Riehl (2000) develops an integrative view of educational administration that draws from normative, empirical and critical literature. She concludes, following key observations from Dillard (1995) concerning school leadership with respect to diversity, that new philosophical, epistemological and sociological understandings of practice are needed, along with the recognition of this work as a discursive practice (thereby meriting the use of critical perspectives and emerging theoretical orientations, along with more active and ongoing research) to ensure progress in the field. In a more recent comparative case study of transformative leadership in demographically changing schools in America, Cooper (2009) adds to this call by suggesting that, "current educational leaders, scholars and activists need to draw 
from an array of relevant sources - philosophical and practical - to further their understanding," noting that, while relevant frameworks for new understandings have been developed by researchers in recent years, "there is, however, a dearth of literature conceptual and empirical - that ties transformative leadership to the complexities and conflicts that demographic change presents" (p. 698). Regarding the challenges involved with understanding the intricacies of the principal's role, Crow (2007) also acknowledges the limitations of existing literature (specifically concerning "what successful leaders do") that, "typically relies on some older studies and tends to be normative in its orientation," and suggests that international comparative studies can be, "valuable in extending our understanding of these leadership practices beyond normative and uniform findings" (p. 74). Mitchell and Ortiz (2006) note that, "educational administration scholars are now able to trace the evolution of their own thinking and to recognize that competent professional practice is informed and transformed more by understanding what counts as useful knowledge than by the individual elements that might constitute a repertoire of reliable research findings. In that regard, the field stands ready to move forward...in shaping and empowering professional practice" (p. 50). Their review of educational administration scholarship, outlining the evolution of related knowledge across four epochs, explaining how the theory movement (or third epoch in their historical outline) gave way to clashing forces and agendas, beginning in the 1970s, that subsequently complicated fundamental epistemological debates and foundational views of education practice. Mitchell (2006) concludes that, ...the theory movement was right to emphasize the explicit theoretical modeling of practical action, but it was wrong in thinking that this modeling would become more 
potent by being disengaged from moral commitment... Professional vocation is the essence of a moral seriousness that simultaneously recognizes that all practical action is directed to moral ends and makes the primary aim of professional action the illumination of cultural meaning systems and the building of support systems enabling other members of the culture to acquire and pursue meaningful life projects. (p. 258)

Gunter (2016) asserts that, in the field of educational administration, "the consistent message is that leadership is a power process that is about influence, and where there tends to be an acceptance of Transformational Leadership as a functional visionary process led by the principal, with modifications as new hybrids are developed" (p. 120). In her intellectual history of educational administration, Gunter explains, "the idea of the Theory Movement remains influential, and it is evident either in the continued attempts to synthesize the plurality through the formation of a knowledge base or in sidestepping this and in retaining prediction and certainty that are evident in the continued dominance and rebranding of Transformational Leadership" (p. 133). She concludes,

...this intellectual history of school leadership seems to indicate that not only should history as a resource be rethought for research and practice, but how the public context in which we do this needs to be reimagined. This has implications for knowledge actors in a range of organizational sites, but it speaks in particular to schools and the universities as spaces for Knowledge Production. (p. 194)

Bolman and Gallos (2011) speak directly to the challenges of leadership in higher education and adapt the meta-framework from Reframing Organizations (Bolman \& Deal, 2004) for reframing challenges faced by leaders of postsecondary institutions. In Reframing Academic Leadership (2011), Bolman and Gallos highlight the importance of approaching the work of leadership as a developmental journey, involving personal inner growth and "embracing a sense of calling" that fuels the courage to learn and "lead with soul" (p. 202). 
Their holistic rendering of "the sacred nature of academic leadership" (p. 219) echoes the findings and core messages from Lyman, Strachan and Lazaridou (2012) and their stories of women educators around the world, documented in Shaping Social Justice Leadership. Their review of scholarship related to women in education working for social justice, citing Grogan and Shakeskaft (2011), highlights five characteristic approaches of how women lead - including relational, spiritual and balanced leadership, along with leading for learning and social justice while noting a perspective shift and identifying "diverse collective leadership" as an emerging practice, "building on approaches common to women's leadership" (p. 8) that is aligned with transformative leadership principles.

Through an extensive multi-campus study, William Tierney (1989) explores the curriculum as a core venue for transformative leadership in postsecondary education. He explains how an institutional mission-driven culture can appropriately guide this process:

...the strength of what the mission says or does not say helps define the parameters for action and discourse. Most often, action and discourse occur on the terrain of curricular planning. The language that people use and the discussions that are held surrounding curricular change locate specific social practices and relations. Such discussions ultimately link up to the relationships between ideology and culture... The curriculum is the locale for debating what it means to be American....and of consequence, what it means to live in a democracy. (p. 134)

In this way, transformative leadership, through cultural knowledge work, can guide the process of charting paths toward "democratic vistas" through the contested landscape of the curriculum.

Shields (2004) recommends a social justice oriented theoretical framework of transformative leadership for leveraging meaningful change that is "deeply rooted in moral and 
ethical values in a social context" (p. 113) for the purpose of overcoming "pathologies of silence" connected with status quo conditions that have marginalized significant numbers of students in the American system. This framework highlights the importance of developing caring relationships and facilitating moral dialog with students, among all constituents within schools, and throughout the community. As Shields points out, integral to the practice of transformative leadership is a socially responsible approach toward inclusivity that recognizes and appreciates cultural, ethnic and social class differences among stakeholders. In her recent study of two social justice minded principals, Shields (2010) distinguishes leadership practices that are transformative from those that are considered transformational or transactional, pointing out that transformative approaches involve actively questioning and critiquing the persistence of social inequities that are reinforced in education systems with an intent to leverage meaningful change for social justice that promotes progress in both individual and collective contexts. Shields (2013) also identifies "eight key tenets of transformative leadership theory" (p. 21) - later referred to as fundamental characteristics (p. 121):

- the mandate to effect deep and equitable change ;

- the need to deconstruct and reconstruct knowledge frameworks that perpetuate inequity and injustice;

- a focus on emancipation, democracy, equity and justice;

- the need to address the inequitable distribution of power;

- an emphasis on interdependence, interconnectedness, and global awareness;

- the necessity of balancing critique with promise; and

- the call to exhibit moral courage. 
William Foster, whose work Shields acknowledges prominently in several publications, calls on educational leaders to understand and challenge systemic conditions that enable their practice to serve as a vehicle for bureaucratic social control. Drawing on the work of poststructural and critical theorists, in his last manuscript, Foster (2004) highlights the suggestion that, "an administrative mentality pervades modern society and is exerted through what Foucault labeled technologies of thought," and these technologies - control of numeracy, control of information, and control of language - "although not completely controlling, do exert a primary influence on the way we think and act, and they are exerted, in a sense, through the influence of leadership" (p. 177). This condition is emphasized with regard to the need for developing transformative leadership practice in education that rethinks this work in empowering terms, including recognizing the influence of embedded power structures, acknowledging the importance of local contexts and re-conceptualizing educational organizations as communities. Anderson (2004), honoring Foster, suggests that this unfinished theoretical work represents, "a new direction for the field of educational administration," since, “according to Foster, even traditional notions of power and politics have changed drastically thereby calling for new ways to study their more subtle and unobtrusive manifestations" ( $p$. 243). The transformative educational leadership approach encouraged by Shields $(2003,2004$, 2010) cites the work of Foster, Freire, Brown and other social justice oriented literature in the development of her framework aimed at facilitating the creation of respectful "communities of difference" that challenge status quo conditions through authentic moral and ethical dialogs. 
In A New Agenda for Research in Educational Leadership (Firestone \& Riehl, Eds., 2005), a chapter by Furman and Shields (2005) proposes a framework and methodology concerning "leadership for democratic community and social justice in schools." Their interactive framework for transformative leadership inquiry involves five core dimensions of leadership moral and ethical, communal and contextual, processual, transformative, and pedagogical and emphasizes a dedication to dialogic methods and relational approaches to understanding local contexts (See Figure 1, p. 30). This framework, along with the articulation of cross-cultural transformative leadership offered by Shields (2003) and her other more recent iterations of social justice oriented leadership practice, represent a culmination of theoretical development that is appropriately suited for diverse contexts that include underrepresented students, particularly for those that include Indigenous students, along with a systems-level scope.

\section{Postmodern Shifts Across Domains}

Significant parallels are represented in literature related to CREL from both organizational and educational domains of research, and one key theme pertains to postmodern shifts (Lyotard, 1984) occurring across these domains involving growing calls for the recognition of multiple perspectives and epistemological standpoints, along with the value of critical analysis. For instance, Casey (2006) highlights the contested nature of rationalities in contemporary global organizational research and acknowledges the utility of emerging postmodern philosophical orientations and feminist theoretical perspectives, particularly ecofeminism, for authentically in-depth organizational research efforts. This is one of many 
examples of organizational research identifying similar epistemological considerations highlighted across educational studies.

Another example of resonant postmodern shifts, beyond those already noted, in the domain of educational research is found in the philosophical examination of standpoint epistemology provided by Boyles (2009), who argues that, "ecological thinking and standpoints for knowing should be primary elements in a general theory of knowledge for reconstructing schools and schooling as sites for agentic knowing" (p. 125). Drawing from the work of Lorraine Code (2006) and incorporating the "new coherence theory" of Alcoff (1996), the notion of "strong objectivity" from Harding (1995), and the concept of "situated knowledges" from Harroway (1988), Boyles (2009) echoes their scholarly challenge to orthodox epistemologies and argues for, "a new look at epistemology as a means of helping both students and teachers in their quests for understanding and meaning-making" (p. 134-135). He explains that, "by asserting standpoint epistemology that is not relativistic... they replace standard accounts of knowledge and knowing subjects with an embodied, actively engaged, contextualized social knower. I name this social knower 'student' and 'teacher' in order to bridge the ecological and epistemological with schools and schooling" (p. 126).

Similar connections across domains of educational and organizational research are represented in literature featuring unique applications of standpoint theory. For example, in their study of African American women principals of urban schools, Bloom and Erlandson (2003) use standpoint theory (and "episodic narratives" or "critical tales") to encourage meaningful interpretations of Black feminist perspectives in educational administration ( $p$. 
342). Related claims pertaining to the utility of standpoint theory in studies of educational leadership contexts are also resonant with shifting perspectives in the domain of management scholarship, as demonstrated by Adler and Jermier (2005) in their examination of the relevance of standpoint theory in the study of public policy, following guidelines offered by the Academy of Management (AOM). They conclude: “The 'AOM Code of Ethical Conduct,' which encourages a multiplicity of perspectives, should serve as a basis for more reflexive inquiry and more progressive contributions to public policy" (p. 944).

From both organizational and educational domains of research, the inclusive nature of recommended approaches toward understanding concepts and practices related to CREL is fairly consistent across these domains and related fields. To clarify this point, the term inclusive refers not only to the recognition of diverse subjects and unique contexts of research represented in related literature, but also to the range of theoretical orientations that are deemed appropriate by researchers in their processes of inquiry and analysis. Whether approached from the vantage points of administrators, instructors, other personnel constituencies or other stakeholders (students, families and communities) - in contexts of leadership, pedagogy or policy, and related to micro-level or macro-level examination (focused on programs, institutions, or systems, across sectors and levels) - the consistent justification for developing more inclusive, comprehensive and pluralistic understandings of elusive sociocultural elements, complex relational phenomena and widely varied conceptual interpretations should be given serious consideration in the study of CREL. Changing trends that constitute 
postmodern shifts across disciplines and domains of research are significant with regard to applicable theoretical and practical recommendations widely respected among researchers.

\section{Indigenous Theory and Research}

While related literature reviewed from the domain of education pertaining to underrepresented populations and students of color commonly includes Indigenous students and their unique concerns within the scope of underrepresented groups in general terms, Castagno and Brayboy (2008) point out the limits of existing culturally responsive scholarship and its intended impact concerning issues of equity with respect to Indigenous students specifically. They make the following assertions in their review of literature related to culturally responsive schooling (CRS) for Indigenous youth:

Change is clearly needed. Although CRS has been advocated for over at least the past 40 years, we still see schools and classrooms that are failing to meet the needs of Indigenous students. The increased emphasis on standardization and high-stakes accountability under the No Child Left Behind Act of 2001 (NCLB) seems to have resulted in less, rather than more, culturally responsive educational efforts and more, rather than no, Indigenous children left behind in our school systems. We want to suggest that although the plethora of writing on CRS that we review here is insightful, it has had little impact on what teachers do because it is too easily reduced to essentializations, meaningless generalizations, or trivial anecdotes - none of which result in systematic, institutional or lasting changes to schools serving Indigenous youth. (p. 942)

Following a definition of the culture concept that is, "simultaneously fluid and dynamic, and at times - fixed and stable" (p. 943), and using the metaphor of an anchor to illustrate the complexities of culture as an evolving combination of three cultural forms identified by Borofsky, et al. (2001), Castagno and Brayboy (2008) provide a historical review - tracing back to the Meriam Report (Meriam, Brown, Cloud, Dale, Duke \& Edwards, 1928) and highlighting 
subsequent congressional reports and legislation connected mainly with Native Americans and Alaska Natives - that examines significant shifts and changes in educational policy, practice and outcomes culminating in the era of NCLB. They claim that, "schools are moving further away from providing an effective, high-quality and culturally responsive education for Indigenous youth" (Castagno \& Brayboy, 2008, p. 946). Beyond demonstrating the wide range of conceptual interpretations and definitions connected with CRS, they argue that elements of sovereignty and self-determination, racism in schools, and Indigenous epistemologies represent "a critical hole in most of the current work on CRS" related to Indigenous contexts (p. 948).

Their exploration of Indigenous epistemologies cites the work of Battiste $(2001,2002)$ and others that recommend acknowledging the unique nature of various Indigenous epistemologies (and the hazards of making inappropriate generalizations across cultural knowledge systems). They also recognize the importance of understanding the relationships between Indigenous and dominant mainstream knowledge systems as intertwined (rather than viewing them as in opposition to one another) - thereby reinforcing the value of conceptualizing epistemologies as interwoven "threads" of knowledge that combine uniquely in local communities (Meyer, 2001). As Castagno and Brayboy (2008) explain: “Multiple epistemologies can and must coexist within school settings... and we would likely serve Indigenous youth more effectively if we did a better job integrating multiple epistemologies within our pedagogy, curricula and educational policies" (pp. 952-953).

Suggestions made by Demmert and Towner (2003) highlighted in a review of literature concerning the influences of culture based education (CBE) on the academic performance of 
Indigenous students - which examines three major underlying theoretical perspectives connected with CBE: Cultural Compatibility Theory, Cognitive Theory and Cultural-HistoricalActivity Theory (CHAT) - are echoed by Castagno and Brayboy (2008). They note the similarities represented in prevailing theories related to $\mathrm{CBE}$ and the value of considering multiple theoretical explanations for education outcomes among Indigenous students. In the case of these theories, "they all agree that education ought to be based on personal and communitylevel connections to students' experiences, cultures and knowledge" (Castagno \& Brayboy, 2008, p. 958).

They identify the Alaska Standards for Culturally Responsive Schools (Assembly of Alaska Native Educators, 1998) as, "providing an exemplary model in developing its own [Alaskan] cultural standards for curriculum... to complement standards set forth by external government agencies to ensure that local cultures and languages are represented in school curricula" (Castagno \& Brayboy, 2008, p. 965) in all educational environments at all levels. As already noted above, the Alaska Standards served as a template for the NHMO Guidelines (NHEC, 2002) later developed in Hawai'i, reflecting a similar stance and intention to complement externally imposed standards through more culturally relevant curricula and pedagogy, from a Hawaiian perspective. After considering the Alaska Standards and Hampton's (1988) criteria for an "Indian theory of education" as helpful guides for addressing school-wide and district-level issues related to CRS (Castagno \& Brayboy, 2008, pp. 975-976), their review of related case studies and key themes represented among them recognize the importance of "localizing curriculum and pedagogy," while demonstrating that, "knowledge, norms, values, resources 
and epistemologies must be viewed as legitimate and valuable," and highlighting, "the ways in which Indigenous students are engaged and learning school knowledge at the same time and through experiences that also facilitate the learning of their local community knowledge, culture and epistemology" (p. 981).

Kawagley and Barnhardt (1998) write, "when examining educational issues in indigenous settings, we must consider the cultural and historical context, particularly in terms of who is determining what the rules of engagement are to be, and how those rules are to be implemented...the future of indigenous education is clearly shifting toward an emphasis on providing education in the culture, rather than education about the culture. From this we will all benefit" (pp. 15-16). They note the importance of efforts reconnecting education with Native ways of knowing place and culture, with hopes of informing how to, "devise a system of education for all people that respects the philosophical and pedagogical foundations provided by both indigenous and western cultural traditions" (p. 2). In a later article, Barnhardt and Kawagley (2005) assert that,

...by utilizing research strategies that link the study of learning to the knowledge base and ways of knowing already established in the local community and culture, Indigenous communities are more likely to find value in what emerges and to put new insights into practice as a meaningful exercise in self-determination. In turn, the knowledge gained from these efforts will further our understanding of basic human processes associated with learning and the transmission of knowledge in all forms. (p. 21)

In their article "First Nations and Higher Education: The Four R's - Respect, Relevance, Reciprocity, Responsibility," Kirkness and Barnhardt (2001) reframe issues related to Indigenous student underrepresentation in higher education. In the process, they explain that, "First Nations students and communities are seeking an education that will also address their 
communal need for 'capacity-building' to advance themselves as a distinct and self-determining society, not just as individuals" (p. 6). They acknowledge the central importance of empowerment as, "at the heart of First Nations participation in higher education," and assert that, "what First Nations people are seeking is not a lesser education, and not even an equal education, but rather a better education - an education that respects them for who they are, that is relevant to their view of the world, that offers reciprocity in their relationships with others, and that helps them exercise responsibility over their own lives" (p. 14). Galla, Kawai'ae‘a and Nicholas (2014) document how an international collaborative approach toward developing Indigenous Academic models builds on the work of Kirkness and Barnhardt, utilizing a framework of six $\mathrm{R}^{\prime} \mathrm{s}$ - respect, responsibility, relevance, reciprocity, relationships and resiliency.

From a systems-level vantage point, Meyer (2005) describes the role of Indigenous epistemologies in relation to higher education quality assurance efforts undertaken by the World Indigenous Nations Higher Education Consortium (WINHEC) - "a multi-nation effort to accredit, empower and thus affirm native control of indigenous higher learning" (p. 1). She explains a key reason why WINHEC began - "Indigenous peoples must interpret our systems of higher education embedded in our own triangulation of meaning" (p. 6) - and describes the three key elements in this triangulation process that represent the focal points of WINHEC quality assurance efforts: Language, Culture and Spiritual Beliefs. These three elements connect with fundamental concepts of Mind, Body and Spirit, and Meyer explains, "in every ancient system that has endured and flourished throughout the world there is a recognition 
and use of these three categories to describe the complexity of life in a fluid and beautiful manner" (p. 6), which are respectively represented by examples of a) facts, logic and metaphor, b) the exterior, the interior and the transpatial, c) empiricism, rationalism and transcendentalism, and so on. This manner of epistemological triangulation is explored in the context of several ancient traditions, including those of the Maori and Hawaiians, to demonstrate the WINHEC rationale and approach toward quality assurance in Indigenous higher education efforts around the world.

Additional literature pertaining specifically to Indigenous cultures in the Pacific region reinforces the importance of inclusive approaches and recognizing the significance of local contexts in educational research efforts. On the subject of decolonizing pacific studies in higher education, Thaman (2003) notes that, "valuing indigenous ways of knowing usually results in mutually beneficial collaboration between indigenous and nonindigenous peoples, and improves their treatment of each other as equals" (p. 11). While admitting being "attracted to postmodernism," and related theoretical orientations, Thaman asserts that, "postmodernism does not provide all the answers," and offers the following explanation:

In my view, its ahistorical representation of social life as a continuing conflict between the colonizer and the colonized denies Oceanic cultures a past without Europeans and their colonizing activities... To view the Pacific only from the perspective of European colonization does not do justice to the region's indigenous peoples... I suggest that indigenous worldviews are good for the future of university studies. An inclusive and holistic way of thinking champions stewarding nature, participating in community, and valuing interpersonal relationships. It compliments beliefs in rational objective thinking, suspicion of emotions and feelings, material productivity, and personal autonomy. (2003, p. 12) 
Acknowledging the value of Indigenous wisdom (and its pre-modern roots) in the postmodern era, Thaman concludes that, "today, while modern global technology allows us to be detached from the earth and from people, indigenous wisdom is about the connectedness and interrelatedness of all things and all people" (p. 12).

Hviding (2003) also recognizes the value of embracing pluralistic and inclusive perspectives with respect to Indigenous knowledge and the importance of focusing on the spaces "between knowledges" in the context of research connected with the Pacific region:

For Pacific Islands studies, the most important measure is not the number of knowledge fragments known and mastered and put to use; it is the gaining of insight into processes that tie such fragments of knowledge and understanding together in mutual inspiration, support, and dependence. The approaches of different knowledges, whether institutionalized as disciplines or existing in local, unwritten forms, can yield insights into different relations and processes ranging across the cultural, the social, the political, the ecological, and more. Interdisciplinarity implies the ability to combine different knowledges and their insights into significant projects and practices - formulating innovative, more proper research for reaching greater, more holistic understanding of how Pacific worlds have been, are, and will be constituted and remade. (pp. 65-66)

In reference to anti-colonial strategies for recovering and maintaining Indigenous knowledge, Simpson (2004) adds that, "academics who are to be true allies of Indigenous Peoples in the protection of our knowledge must be willing to step outside of their privileged position and challenge research that conforms to the guidelines outlined by the colonial power structure and root their work in the politics of decolonization and anticolonialism" (p. 381). These articulations of key considerations related to Indigenous populations reflect the importance of approaching critical social research in Indigenous contexts authentically and conscientiously. Regarding the specific cases that are the focus of this study, Kawai'ae'a and Wilson (2007) summarize the history of, "efforts to develop structures providing teachers to revitalize 
our home islands' indigenous language over the past twenty-five years," (p. 38) at the UHH$\mathrm{CHL}$, "where we work with others to train teachers through the Kahuawaiola Indigenous Teacher Education Program as part of a larger developing system for Hawaiian language revitalization" (p. 45). They recount the evolution of the UHH-CHL's role in movements for Native Hawaiian uplift, and the development of the Kumu Honua Mauli Ola philosophy, "a set of guiding principles that has supported the vision and aligned the direction of the Punana Leo, Ka Haka 'Ula O Ke'elikolani [CHL], and the Papahana Kaiapuni Hawai'i schools," which originally was, "written solely in Hawaiian and based in Hawaiian traditional teachings" (p. 45). They also recount the subsequent development of Na Honua Mauli Ola-noting that it has been endorsed by, "many Native Hawaiian serving organizations, programs, schools and others," and that, "the State Department of Education is using the cultural guidelines to clarify expectations in a wide variety of Hawaiian programs" (p. 45). One area of progress highlighted is the integration of teacher preparation with graduate education; and, as a result of the combined programs offered by the UHH-CHL, "all new faculty are expected to teach over the broad range of levels, from preschool through graduate school, which exists within the structure of the College" (p. 50). The Kumu Honua Mauli Ola philosophy that the UHH-CHL is rooted in, "leads us to seek a healthy group mauli (life force) through application of its concepts of honua (places/situations/entities), piko (connections), and 'ao 'ao (distinctive attributes and features) to our interactions and relationships with places, people, things, and ideas... Kahuawaiola is part of a holistic approach to developing Hawaiian medium educational structures and policies" (p. 52). This localized, holistic, culturally responsive approach has involved being, "very active 
at a national and international level in the development of models and institutions to nurture the survival of indigenous languages and cultures while providing high quality educational programs," and, through the development of a consortium in partnership with APL, "have served as a national model and visitation site for Indigenous groups conducting and exploring education through Indigenous languages," (p. 51) thereby reflecting their global significance.

\section{Summary: Leadership Revisited}

This review of relevant highlights from organizational, educational and Indigenous domains of theory and research reflects notable themes and parallels related to the topic of CREL and how it can be appropriately understood in theoretical and practical terms. Inclusivity is a core guiding principle echoed across these domains; this is clear, as already mentioned, in relation to collective participation, pluralistic theoretical and epistemological foundations, and in various other ways. Localization is another key theme, particularly for centrally guiding processes as a whole, and to ensure contextually situated understandings for enabling contextually relevant strategy and action. Collective, holistic, relational, ecological and interdependent understandings and awareness are similarly connected with appropriately engaged values-driven approaches across these domains, as well.

Postmodern shifts and critical stances widely represented in Western strands of related theory and research reviewed here signify trends that are aligned with resonant calls from Indigenous researchers for revisiting, rethinking and reestablishing common approaches toward education, leadership and social justice in a contemporary global context. Recognizing the 
limits and obsolescence of long-embedded Western traditions and paradigms, reevaluating dominant constructs and structural systems, and enabling more ways for post-industrial, postcolonial and non-Western-centered discourse and activity to develop, all represent important complementary considerations for pursuing an authentic understanding of CREL from a Western standpoint, despite inevitable limitations. These considerations can encourage more meaningful conceptualizations of CREL and inform effective approaches toward being culturally responsive through developing deeper understandings of cultural differences, the benefits of diversity, and significant lessons to be learned from history.

\section{Theoretical Frameworks}

Due to the administratively oriented nature of this CREL case study and the nonIndigenous vantage point of the researcher, the primary theoretical frameworks used in this research are drawn mainly from the organizational and educational domains of literature reviewed previously. The framework for transformative leadership developed by Shields (2003, $2004,2010)$, and the related interactive framework and methodology for leadership inquiry proposed by Furman and Shields (2005), are adapted for use in the analysis of CREL characteristics, elements and processes in organizational and operational terms. These primary frameworks are applied in conjunction with relevant theory and research drawn from the Indigenous domain of literature in the analysis of non-Western dimensions of CREL - including the work of Battiste $(2001,2002)$, Meyer (2001) and others concerning Indigenous epistemology, conceptualizations of culture (Borofsky, et al., 2001; Geertz, 1973, 1983), and 
unique culture-based education considerations identified by Demmert and Towner (2003), Castagno and Brayboy (2008), Kawagley and Barnhardt (1998) and others.

This adaptation of the interactive framework and methodology for leadership inquiry from Furman and Shields (2005) and the transformative leadership framework developed by Shields $(2003,2004,2010)$ is fully aligned with the more recent praxis framework for social justice leadership proposed by Furman (2012), which entails a similar multi-dimensional framework defining regions for developing capacities in leadership practice that Furman deems crucial. While the utility of these frameworks for leadership preparation programs seems promising in differentiating and mapping core areas for developing leadership competencies, the application of a multidimensional framework for understanding transformative leadership practice in this study is aimed at examining key dimensions of collective capacity building related to the cases of exemplary CREL practice studied here - and it is additionally useful in the analysis of key CREL characteristics, elements and processes in organizational and operational terms. This blending of research perspectives is undertaken for the sake of approaching this organizationally-focused analytical work appropriately, albeit with understandable limitations, and honoring the unique Indigenous history, epistemology and cultural knowledge informing the innovative processes and products that are the focus of this research accordingly - bearing in mind that CREL can't be understood from a Westerner's vantage point in the same ways it can be understood from an Indigenous researcher's vantage point. This key limitation provides further motivation to pursue the most authentic and representative outcomes possible in this research, in an effort to achieve clearer articulations of analyses and findings appropriately 
suited for the largely Western venues and likely audiences for this dissertation research product. 
CHAPTER III

\section{RESEARCH DESIGN AND METHODOLOGY}

In their introduction to the third edition of The Sage Handbook of Qualitative Research, Denzin and Lincoln (2005) describe the larger history of qualitative research in terms of eight phases or "moments" characterizing the evolution of the field. The "fractured future" they predict for the ninth moment (coinciding with this study) is later revisited by Denzin (2010), who suggests that the state of paradigmatic conflict related to qualitative research in that moment represents a continuation of a dialectic process that has played out through three key paradigm wars: "the postpositivist war against positivism (1970-1990); the wars between competing postpositivist, constructivist, and critical theory paradigms (1990-2005); and the current war between evidence-based methodologists and the mixed methods, interpretive, and critical theory schools (2005 to present)" (p. 421). In Denzin's words:

As members of a larger moral community, we all need to draw together so we can share our problems and experiences with new discourses. We need a moral and methodological community that honors and celebrates paradigm and methodological diversity. As fellow travelers we need research agendas that advance human rights and social justice through multiple forms of qualitative research (p. 425).

This study is informed and guided by analyses of the evolving qualitative research domain offered by Denzin, Lincoln (2010), and others (Guba \& Lincoln, 2005; Howe, 2009; Wiseman, 2010) - and inspiration is drawn from their spirited calls for more meaningful approaches toward navigating new frontiers in qualitative research for the public good.

Greckhamer, Koro-Ljungberg, Cilesiz and Hayes (2008) echo calls for methodological reconsiderations in their deconstructive demystification of interdisciplinary qualitative research 
practice. They suggest more transformative exploration of "the territories on the map of knowledge" through qualitative inquiry in order to "keep researchers on the move, questioning the governance of knowledge organization and its legitimacy" (p. 328). They conclude their analysis by stating, "we call the field for more reflection through institutional analyses and deconstruction of taken-for-granted realities and myths. This may be the first step of a true praxis (Friere, 1993) that aims to transform the territory of knowledge production through communal action" (p. 328) - thereby enabling epistemological and paradigmatic boundaryspanning that can promote meaningful new syntheses and convergence.

Weber (2007) proposes a new global research agenda for education that relies heavily on qualitative methodologies for the purpose of developing more representative understandings of the unique local contexts of postcolonial societies and the challenges they face with regard to education research, policy and practice. In the context of the present day, Weber explains, "postcolonialism seeks to explore the epistemological 'third space' in the dialectic of global and the local," (p. 301) thereby enabling more meaningful navigation of comparatively uncharted research territory in the developing world. This type of exploratory process is reflected in the previously mentioned work of Kawai'ae'a and Wilson (2007), who eloquently outline the evolution of the CREL innovations that are the focus of this study in their documentation of efforts in the UHH-CHL Kahuawaiola Indigenous Teacher Education Program. Through more than a decade of innovative collaborations among an international network of higher education institutions, including the $\mathrm{UHH}-\mathrm{CHL}$, their evolving CREL efforts have helped drive the development of new "free spaces" for revitalizing Indigenous knowledge systems 
around the world through collaborative international Indigenous language and culture education programs (Galla, Kawai’ae‘a \& Nicholas, 2014), among other efforts.

Methodologically, this study honors calls for new social justice oriented research echoed throughout the changing landscape of the qualitative research domain, along with resonant calls represented across other realms of research and literature reviewed previously that speak to educational leadership for social justice (Castagno \& Brayboy, 2008; Kawagley \& Barnhardt, 1998; Shields, 2010). The three-part focus of this case study and the ongoing work of the communities involved represent efforts I sought to actively support (despite being a newly arrived cultural outsider) as a resident stakeholder and local education professional before I sought to document stories of their evolution as a researcher; as a non-Indigenous researcher, the type of documentary effort I strive for in this study is most appropriately approached in a situated manner, as a stakeholder with sufficient working knowledge of the unique Hawaiian education system and socio-cultural context (and with local relationships already established) to pursue deeper understanding (despite not being fluent in Hawaiian language). Beginning the study design process as a resident stakeholder naturally fueled a more participatory approach toward the role of observer (though this study is not a participatory observation by strict definition) and encouraged deeper appreciation of reciprocity, ethical issues, reflexivity and other important considerations in this interpretive analytical study of Indigenous CREL innovations. While aspects of ethnographic, phenomenological and action-oriented research are somewhat applicable in this research effort, it is a simply structured case study by design. 
The resultant design for this study, years in the making, was impossible to visualize as a student in Illinois completing coursework before I had chosen to relocate to rural East Hawai'i, following advice from my initial contact in the situation - who told me that the heart of the movement I wanted to learn more about was there, on the Big Island, and that getting to know it would require living there for a while. I wanted to find ways to get involved in this situation and support the progress of the movement however I could, for my own reasons, in part through determining a mutually beneficial approach to the study once I settled there. I chose to move there permanently - not for the sake of the research, but to build a new life - confident that a worthwhile study could be developed and undertaken as I found ways to get involved in local CREL efforts there.

As I became more familiar with the innovations focused on this study through my own local integration, I learned that the stories of these significant CREL efforts had not yet been recorded, and this seemed to represent a crucial void in the local historical record. While meetings, writing activities and formal actions related to these efforts are documented in some manner, there is little record of more complete articulations and illustrations of how these efforts as a whole grew within the evolving movements of Hawaiian language and culture revitalization and Native Hawaiian education in the context of a uniquely changing landscape of organizations and systems in Hawai'i through the early $21^{\text {st }}$ century. Thus, documenting these stories from leaders of these efforts became a priority in this research.

As acknowledged by Kawai'ae'a and Wilson (2007) and participants in this study, the CREL innovations that are the triple focus of this research represent, in part, a contemporary 
record of cultural knowledge, traditions and history formerly unwritten and transmitted orally, largely through stories. Documenting personal accounts from leaders of these CREL efforts thereby generating a public record of how these efforts were undertaken through stories of their development - represented a meaningful contribution I was capable of facilitating as a researcher for a community that values these types of stories highly. Therefore, the simple and adaptable case study structure of this research effort, guided by the documentarian role, allowed for approaching the qualitative study of CREL in a mutually beneficial manner.

The documentary aspect of this study is a crucially important design element, anchoring the research functionally in a mode of active witnessing and, in the process, generating a new record of significant oral histories offered by participants. In order to facilitate rich dialog concerning CREL with leaders of exemplary Indigenous efforts - in a manner that yields rich data speaking to this complex topic, while promoting mutually beneficial outcomes among participants through promoting awareness of the innovations studied - this research is intentionally designed to be sufficiently adaptable to maximize its potential utility, meaning and value for everyone involved. In this way, the nature of the study is, by design, greatly influenced by the nature of the place and its people - a result that highlights the value of thoughtfully situated preparations to ensure a study design that is culturally aligned and locally valuable. Being an active stakeholder enabled clearer demonstration of my intentions as a researcher, strengthened my efforts to personally build trust with participants on their terms, and allowed for privileged access to information, moments and situations rarely accessible by outsiders - all 
directly resulting from a situated understanding of local traditions and cultural protocol, and how to properly honor them.

This unique qualitative case study applies multiple theoretical frameworks, data gathering methods and analytical processes in an effort to gain a more complete understanding, from a Western standpoint, of CREL as it exists in the unique context of the Native Hawaiian education movement. The composite theoretical framework adapted from Shields $(2003,2004,2010)$ in combination with the interactive framework and methodology for leadership inquiry proposed by Furman and Shields (2005), as explained previously, are utilized to explore organizational and operational aspects, elements and dimensions of CREL represented in the innovative processes and products connected with the development and updating of the NHMO Guidelines and KHMO Philosophy Statement. A multi-modal approach toward data gathering and analysis (explained below) is used in this study in order to arrive at more representative and meaningful findings concerning the unique nature and significance of the CREL innovations that are the focus of this research.

Following Berg (2009), Patton (1999) and others, this qualitative case study blends multiple methods to suit the unique purposes of this research explained previously. Generally speaking, the process involves a set of studies resembling what have been labeled as collective (Merriam, 2001), multiple (Yin, 2003) and patchwork (Jensen \& Rodgers, 2001) case studies. This study will also include textual analyses and a combination of analytical approaches described by Miles and Huberman (1994) with respect to data collected from available records, survey instruments and face-to-face interviews; other methods directly related to this study 
include conversation analysis (Clayman \& Gill, 2004), discourse analysis (Gee, et al., 1992) and narrative inquiry (Loseke, 2007) - and, while it is multi-faceted, this is a simply structured case study by design.

\section{Participants in the Study}

Participants in this study were identified, in large part, using a snowball sampling method (Patton, 1999), involving referrals offered initially from an established primary contact holding multiple leadership roles related to the study focus - including serving as $\mathrm{UHH}-\mathrm{CHL}$ Faculty, as a member of the NHEC Statewide Council and as a core member of committees that developed KHMO and both editions of NHMO. This referral-oriented sampling method aligns well with local cultural protocol; in Hawai'i, access to elders and leadership circles is most appropriately achieved through personal invitation and introduction by a core member of the family or group involved (personal communication, 2011), rather than by request. Before recruitment began, the study was personally announced and introduced (with appropriate invitations to do so) at meetings of the NHEC, NHMO Pathways Writing Committee and UHH$\mathrm{CHL}$ faculty, along with relevant meetings and conferences involving partner organizations. In accordance with local protocol, I sought (and received) the blessings of key elders and core partner organizations to conduct this research before beginning fieldwork, once IRB approval was secured from Illinois State University, and I am very thankful for this support of the study.

Participants were recruited throughout the state of Hawai'i serving on the NHEC, within the $\mathrm{UHH}-\mathrm{CHL}$ and among core partner organizations. Priority recruits included, first and 
foremost, members of the writing committees who were directly involved in the development of the original NHMO Guidelines (2002), the new NHMO Pathways edition (2015), and the preceding KHMO Philosophy Statement $(1999,2009)$. The members of these writing committees (most of whom are Native Hawaiian) represented a variety of educational organizations (including agencies, institutions and community partners), professional constituencies (including administrators, instructors and service providers) and stakeholder groups (including elders, parents and students) all relevant to this study.

The sample size sought for this study was ten participants directly connected with the development, updating and implementation of $N H M O$ and/or KHMO products. Participants were recruited individually via letter (See Appendix A). Informed consent was ensured through letters of consent explaining the intent of the study (See Appendix B), and these were distributed by mail and/or in person to be signed by participants prior to scheduling interview sessions.

Ultimately, seven participants were interviewed for the study, which was what available time would allow for. Thankfully, the amount of data collected from these seven participants was far more than expected. Each participant's experience in Native Hawaiian education was extensive, spanning education levels, organizational types and leadership domains. While most interviewees are well-known core members of Hawaiian-serving movements across decades, my commitment to ensuring confidentiality for participants in this study results in their names and other identifying terms not appearing in this anonymous record of their stories. Since raw 
interview data could not be included in this manuscript, this record of their stories is also admittedly incomplete.

A professional profile of study participants is included in table form (See Table 1, p. 53). All seven participants in this study held roles as educational administrators and as instructors in Hawai'i over the course of their careers; all seven participants also had professional experience working in both Hawai'i Public Schools and Hawaiian Public Charter Schools (some additionally in private schools, as well). Six participants served on at least one NHMO writing committee, including all three participants who directly contributed to KHMO. All participants were directly affiliated with at least one core sponsoring organization for NHMO and KHMO efforts - four participants have served as UHH-CHL faculty, four have served as APL instructors and/or administrators, and five have served as NHEC council members. Six participants are female, one is male, and five participants identified themselves as Native Hawaiian. 
Table 1. Professional Profile of Study Participants

\begin{tabular}{|c|c|c|c|c|c|c|c|}
\hline & Anne & Beth & Ellen & Jane & John & Mary & Susan \\
\hline $\begin{array}{l}\text { Contributor to } \\
\text { KHMO Philosophy }\end{array}$ & Yes & - & - & Yes & Yes & - & - \\
\hline $\begin{array}{c}\text { Contributor to } \\
\text { NHMO Guidelines }\end{array}$ & Yes & - & - & Yes & Yes & Yes & - \\
\hline $\begin{array}{l}\text { Contributor to } \\
\text { NHMO Pathways }\end{array}$ & Yes & - & Yes & Yes & Yes & Yes & Yes \\
\hline $\begin{array}{c}\text { Worked as } \\
\text { Administrator }\end{array}$ & Yes & Yes & Yes & Yes & Yes & Yes & Yes \\
\hline $\begin{array}{l}\text { Worked as } \\
\text { Instructor }\end{array}$ & Yes & Yes & Yes & Yes & Yes & Yes & Yes \\
\hline $\begin{array}{c}\text { Worked in } \\
\text { HIDoE } \\
\text { Public Schools }\end{array}$ & Yes & Yes & Yes & Yes & Yes & Yes & Yes \\
\hline $\begin{array}{c}\text { Worked in } \\
\text { HIPCS/NHPCS } \\
\text { Charter Schools }\end{array}$ & Yes & Yes & Yes & Yes & Yes & Yes & Yes \\
\hline $\begin{array}{c}\text { Worked as } \\
\text { UHH-CHL Faculty }\end{array}$ & Yes & - & - & Yes & Yes & - & Yes \\
\hline $\begin{array}{c}\text { Worked as } \\
\text { APL Instructor / } \\
\text { Administrator }\end{array}$ & Yes & - & - & Yes & Yes & - & Yes \\
\hline $\begin{array}{l}\text { Served on } \\
\text { NHEC Council }\end{array}$ & Yes & Yes & Yes & Yes & - & Yes & - \\
\hline
\end{tabular}




\section{Data Collection}

To maximize data collected for analysis, a three-phase interview process was conducted with each participant in the study. While the hope was for reflection time to be available between phases, in anticipation of inevitable issues of availability and scheduling, the structure of interview phases was made adaptable to allow for as little as one face-to-face meeting to complete the sessions. A preliminary conversation (by phone, or through an initial meeting) occurred with each participant upon learning of their interest (usually via email) to explain the general nature, purpose and process of the study, allow them opportunities to ask questions, confirm delivery of recruitment letter, obtain informed consent, and determine a comfortable location and schedule for meetings to follow. Survey-based, minimally structured/dialogic and semi-structured approaches were used in combination and designed to be sufficiently adaptable to the range of participant involvement in (and connections with) the focus areas of this study, while allowing for multiple approaches toward key topic areas and improved tailoring of prompts, probes and follow-ups suited for each participant. The structure of phases was adaptable for each participant in terms of location, timing and approach - along with their unique standpoints related to the focus - and guided by participants' individual preferences.

In the first (survey-based) phase, participants were each sent a preliminary survey (submitted electronically via email - See Appendix C), asking six general questions concerning their involvement in Native Hawaiian education and in the development and/or implementation of $\mathrm{NHMO}$ and/or KHMO innovations. The Google Forms secure online platform was used to administer the survey privately and at their convenience. This first phase generally 
contextualized the study for participants and helped set the scene, so to speak, for the subsequent interview phases, which occurred individually face-to-face in a private room at a location that was agreeable to each participant; survey responses offered valuable personal context concerning each participant's standpoint and their views regarding core study topics. In the second (minimally structured/dialogic) phase, participants were asked to recount significant experiences related to the study and tell the story of NHMO/KHMO innovations and how these products were developed and implemented, along with the story of the wider Native Hawaiian education movement, from their unique perspective (See Appendix D). During this session, in conjunction with recording their stories, participant responses from the previous survey were revisited, and follow up questions suited for each participant were informed in part by their responses to the survey from the first phase. The formulation of individualized probes was guided by participant explanations of their personal involvement in the processes of development and/or implementation of $\mathrm{NHMO} / \mathrm{KHMO}$ products, their participation in the Native Hawaiian education movement, and their work in education locally, all spoken to in the survey from phase one.

In the third (semi-structured) phase, a more conventionally semi-structured interview protocol was utilized, with a core list of 12 questions asked of each participant consistently (See Appendix E), followed by appropriate probes developed in the moment based on their responses and former testimony. The two prior phases made this final session richer in most cases, especially when reflection time occurred between the second and third phases. But even in condensed sessions when the second and third phases were completed in one extended 
meeting (there were four instances of this), sufficient data was gathered for the purposes of this study.

Certain evaluative criteria (Miles \& Huberman, 1994) related to this research should be addressed directly to reinforce claims already made concerning the merits of the unique methodological design and approach of this study. Regarding positionality - the influence of which has been suggested already - there is no escaping the fact that my standpoint influenced the data collection process considerably. However, the documentary component of this study encouraged an adaptive approach that actively minimized this influence in practice, while strengthening my ability to satisfy concerns of authenticity, validity and credibility methodologically. The success of undertaking an adaptive approach toward interviewing, while understandably diminishing the repeatability potential of this study somewhat, more importantly reinforced the value of not letting the inevitable influence of my positionality and other variables prevent me from pursuing research of the highest possible quality. The approach of this study, albeit unconventional, was justified for the sake of seizing a rare opportunity to make meaningful contributions to local CREL movements, public discourse concerning CREL and the qualitative research domain through this unique study.

Each in-person interview was scheduled with participants based on their availability over a 120-day fieldwork timeline. Remote interviewing via phone was resorted to in one case, due to difficulties scheduling a face-to-face meeting during the fieldwork period. As mentioned, in four cases, the three-phase structure was adapted to suit interviewees' busy 
schedules by completing the second and third phases in one extended face-to-face meeting, using the same instruments and approaches toward questioning.

All interviews were audio recorded and transcribed for coding purposes. Transcriptions of interviews were member-checked to verify their accuracy by sending electronic copies of transcriptions (formatted for easy review) privately via email. Transcriptions also documented continual clarification follow-ups and confirmation of my interpretations with participants during the interview process. Care was taken to minimize the potential for any participants to experience psychological harm in the interview process. Participant confidentiality was ensured throughout the research process by maintaining secure and private communications with participants, and pseudonyms were used to identify interviewees in transcriptions, with names and personally identifying terms redacted. All data collected were kept secure using locking storage devices throughout the research timeline. In addition to interview data, documentation from writing committee meetings, related conference sessions, and other relevant records were collected for analysis.

\section{Analysis}

Transcription and coding of data was completed without the use of specialized software programs designed for expediting these processes; with the exception of using common word processing software applications, transcription and coding were both completed manually. A verbatim approach toward transcribing is used for the sake of ensuring clear and complete documentation of participant testimony for the analysis process conducted in this study. 
Codes, themes and categories are identified and analyzed to highlight significant threads of meaning reflected in the data speaking directly to the research questions of the study (Miles \& Huberman, 1994), and a composite transformative leadership theoretical framework (Furman \& Shields, 2005; Shields, 2010) explained previously (see page 41) guides this analysis process. In general, analyses attempt to ultimately distill, as much as possible, the essence of CREL in the Hawaiian context, based on interview data collected directly from participants. More specifically, analyses seek to isolate and characterize significant aspects, salient features, and core elements of CREL represented in participant accounts and other documentation of the innovative processes and products that are the focus of this case study. The analysis conducted here can only begin to speak to the depth and breadth of meaning represented in the rich interview data collected from participants.

A three-phase manual coding process (involving transcripts and audio recordings in combination, which were listened to no fewer than three times while coding) was completed with additional memos generated throughout the process. The first phase focused on descriptive codes; more analytic inferential codes relating to patterns and topics became the focus of the second phase (Miles \& Huberman, 1994); memos generated throughout coding were combined with increasingly analytic codes in the third phase for review. This three-phase coding and memoing process distilled clusters of key elements and themes naturally combining into general categories that align well with corresponding dimensions of the interactive framework and methodology for leadership inquiry offered by Furman and Shields (2005) and, as a whole, this framework appropriately suits general explanation of participants' views of 
CREL, key considerations in their efforts, and core influences in these cases (explained further in the next chapter on findings). 


\section{CHAPTER IV}

\section{FINDINGS}

The value of the unique methodological design and approach of this study is demonstrated in the rich data collected in participant interviews. Although available time allowed for only seven people to participate, the amount of rich interview data collected was beyond what was expected from ten interviewees. The multi-modal interview structure successfully combined survey-based, minimally structured/dialogic and semi-structured approaches for gathering more complete data sets related to core research questions - and, more importantly, allowed for appropriately documenting these incredible stories of Native Hawaiian innovation, uplift and progress.

Key elements and themes identified through qualitative analysis (utilizing a transformative leadership theoretical lens) naturally combined into categories aligned with the five-dimensional interactive framework and methodology for leadership inquiry offered by Furman and Shields (2005). This framework, integrated with transformative leadership theory from Shields (2003, 2004, 2010), was well suited for exploring the complex topic of CREL and the unique nature of these cases. An adapted version of the five-dimensional conceptual framework offered from Furman and Shields (2005, p. 131) is applied here (see Figure 1, p. 61) to organize a summary of selected key elements and themes from data grouped into categories representing each dimension of leadership in this interactive framework. 
Figure 1: Application of Theoretical Framework (adapted from Furman and Shields, 2005). Data Coding Results Summary

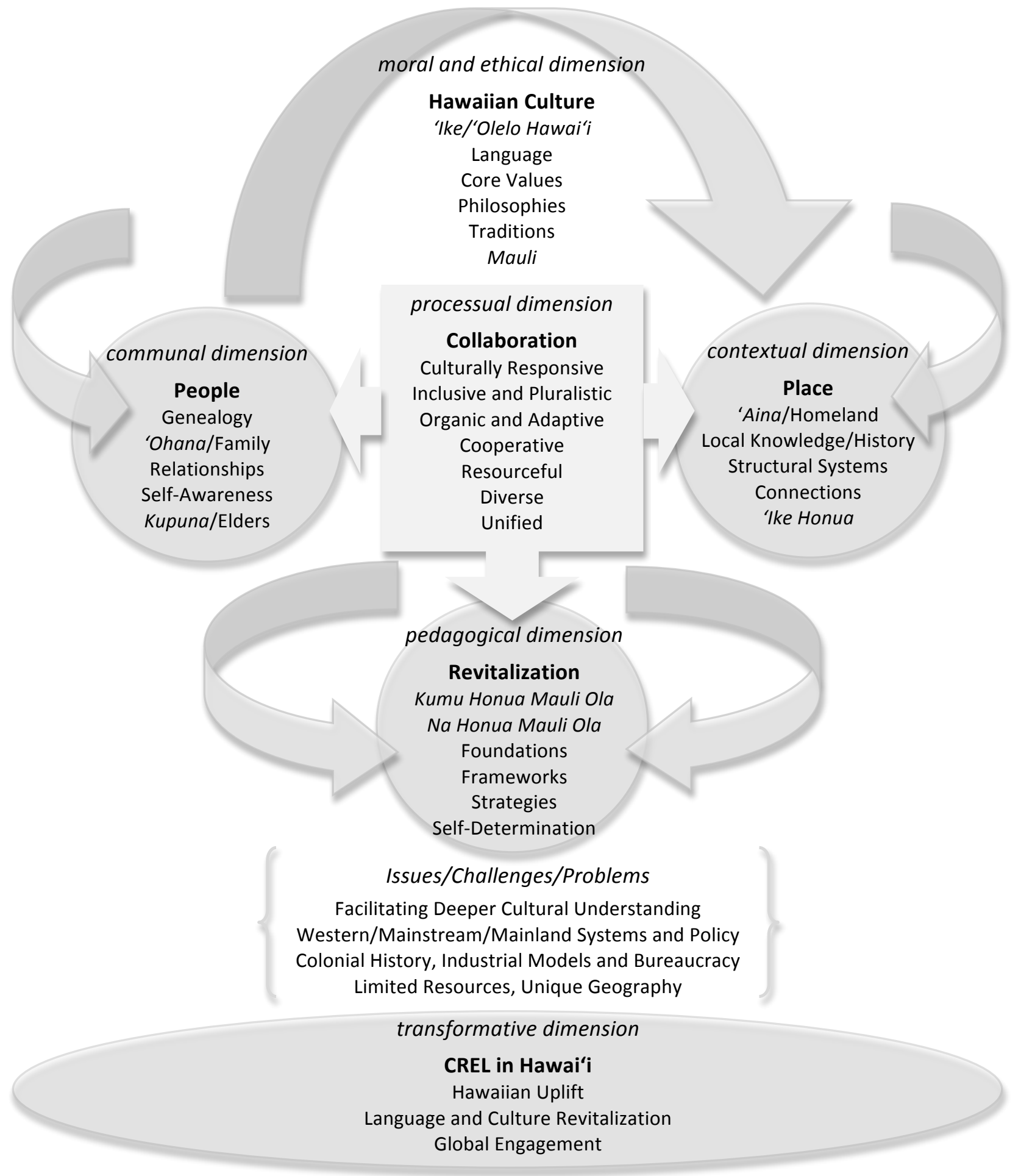


The guiding philosophies, core values and traditions articulated by participants speak to the moral and ethical dimension of these cases. Key elements reflecting the communal and contextual dimensions of these cases are grouped into general categories related to people and place. The processual dimension is reflected in themes related to aspects of collaboration, articulated in a number of ways. Core purposes of CREL strategies are clearly rendered throughout the data, reflecting the transformative dimension. Frameworks and strategies for Indigenous education and cultural revitalization generated in these cases reflect the pedagogical dimension.

In the frame of the moral and ethical dimension, all participants spoke extensively about aspects of Hawaiian culture - core values, philosophies, traditions and the central elements of language and mauli - guiding leadership efforts generating Kumu Honua Mauli Ola and Na Honua Mauli Ola (among other innovations). These specific innovations are historical records of this content and serve as foundational documents providing frameworks for cultivating shared understanding of the Hawaiian cultural context through culturally responsive educational practice. Participants spoke to uniquely Hawaiian aspects of their values-driven practices, while acknowledging the global relevance of these efforts (especially for other Indigenous contexts) and seemingly universal aspects of CREL existing across situations. In the frame of the communal and contextual dimension, several key elements and themes related to identity and behavior (in both individual and group contexts) are represented in the general categories of people and place. For example, genealogy is identified consistently among participants as a fundamental element in the lives of Native Hawaiians, as is one's sense 
of place or 'lke Honua. Self-awareness - including awareness of one's unique genealogical history, interpersonal relationships (especially family), and relationship with their homeland - is acknowledged in a variety of ways as an essential element integral to cultivating shared awareness and collective understandings of Hawaiian culture and context guiding CREL in these cases.

In the frame of the processual dimension, key process-oriented aspects of CREL spoken to by participants are represented in the general category of collaboration. Inclusive, cooperative and organic dialogs and approaches were described consistently by multiple participants, along with key aspects of unified action, working with greater purpose and globalmindedness, in their recounting of CREL efforts in the cases studied. Flexibility, resourcefulness and persistence are all highlighted as key aspects of the adaptive resilience reflected in these cases. Humility, trust and respect are also crucial core elements in participant accounts of CREL processes connected with $K H M O, N H M O$ and other related Native Hawaiian education innovations.

In the frame of the pedagogical dimension, grouped under the category of revitalization, these innovations clearly articulate CREL fundamentals and strategies for all stakeholders. Viewed as a whole, the three innovations that are the focus of this study represent a foundation and framework for education through the language and culture of the people of Hawai'i. Each document reflects unique stages of development in the evolution of CREL strategy and practice among core members of movements in Native Hawaiian education and Hawaiian language and culture revitalization over the course of decades. Some key strategic 
elements highlighted by participants include recognition of good timing and anticipating contextual shifts related to collective action, capacity building and boundary spanning in their efforts to address persistent issues and challenges - including navigating multiple epistemological worlds, overcoming obstacles and constraints related to state and federal bureaucracy, and leveraging limited resources.

In the frame of the transformative dimension, the social justice nature of CREL in these cases is reflected throughout interview data, including working intentionally to uplift the undervalued and underserved, embracing difference and pluralistic perspectives, and courageously endeavoring to revive pre-industrial traditions in a contemporary framework for the benefit of all (not just Native Hawaiians). Participant accounts of the efforts generating KHMO, NHMO and other related innovations reflect deep appreciation for diversity and global responsibility, as demonstrated in continual cross-cultural collaborations with Indigenous groups worldwide and Hawai'i's leadership role in the global Native Language Revitalization Movement (Rawlins, 2011).

Findings are reviewed below in relation to each core research question introduced previously (see p. 12), highlighting key elements and themes identified in interview data.

\section{Research Question:}

What is essential to understand about CREL in the unique context of Hawai' $i$, according to participants in this study? 


\section{Themes:}

Identity, geneology, self-awareness, relationships, family, homeland, local knowledge; Hawaiian culture, language, traditions, philosophies, core values, mauli, history; Culturally responsive, collaborative, resourceful, inclusive, unity, cooperation;

Revitalization, foundations (KHMO), frameworks (NHMO), self-determination, uplift.

According to participants, "who you are and where you're from" is the starting place for Hawaiians, generally speaking. Identity related themes in the categories of people and place were prevalent in participant testimony. Genealogy, self-awareness, relationships with family and homeland, along with knowledge of local history, are all identified as highly valued and having profound influence on individual roles and the shared identity and behavior of groups, organizations and communities in this cultural context. Participants discuss the element of place profoundly in a variety of ways, and the central importance of place in relation to identity, learning and work is rendered clearly and consistently.

Participant accounts of the innovative cases focused on in this study acknowledge that ongoing efforts to increase collective shared capacity of the movements driving language and culture revitalization for Native Hawaiian education have relied greatly on increasing wider awareness and deeper understanding of foundational Hawaiian knowledge (representing themes grouped in the category of Hawaiian culture, including language, core values, traditions and mauli) - thereby clarifying and strengthening unifying shared visions of identity and purpose, while expanding available combined human resources for generating system-wide progress collaboratively (all representing themes pertaining to collaborative process). The identity-driven nature of the values-driven work described by participants in their cultural 
revitalization efforts reflects key aspects of CREL in these cases, as demonstrated by the following quotes from participants:

“...culturally responsive educational leadership...is setting the example as well as mentoring others...to learn new understandings...skills...knowledge...within the context of that culture, whichever culture you're looking at. You know, it will vary from...culture to culture...it includes, but is not limited to...understanding the tenets of the mauli of that culture...So, I think.... when you understand a culture's...values, you're getting the insight into their traditional, you know, knowledge... when you understand how to express or present ideas, or even receive ideas, you're getting insight into their behavior...And then, having a basic understanding of...their spirituality - not their religion, but their spirituality...really is the window to their soul and how to reach them." (Interview with "Susan," November 6, 2015)

"...there has to be things in the process that are reflective of how that culture does things."

(Interview with “Jane," October 5, 2015)

"...the one thing is to tailor your discussion to...the community itself, or the community as it envisions itself to be. Because I think...our movement, the Hawaiian language movement, is envisioning itself to have a living Hawaiian language and culture beyond what is the present case... and so we're acting within the context of that vision that Hawaiian language and culture is the basis of normal life for those who choose to be part of that, and yet, those people have connections to the whole world speaking multiple languages and participating in... the global village...the thing about it is the distinctiveness of the identity of a place or people."

(Interview with “John," December 6, 2015)

“...the context of the history of Hawai'i, you need to be informed, and I think...that's an, an ongoing...learning, and I think leaders have to...I mean, as a leader...you acknowledge that... you're learning, and you acknowledge also that...it's not about you... But it's bringing your... the people along...your students...your peers, you know, your family... That's what you need to understand is that's very important... the cultural context of... the all, the more than just one leader... it's more than you... it's the all... you want... your group to...behave in that way too; 'your leadership is our leadership...we're gonna trust, and you're gonna trust, and we're gonna have this, you know, reciprocal, 'cause it's gonna be...for the good'... That's leadership in the context of Native Hawaiian 
leadership: being able to...bring the people around you...that have that expertise and being able to share; but as the leaders in the organization [APL], having that goal, having that vision, E Ola ka 'Olelo Hawai'I ["The Hawaiian Language Will Live"]...So, uplifting that is...understood amongst them and us in the...staff... All the decisions, when they make a decision it's, it's always for the greater; it's always gonna be for the greater."

(Interview with "Anne," October 7, 2015)

"So that's why they tell you language is the heart of the culture; you can do a lot of cultural stuff, but you don't understand it completely unless you know the language... I mean, you don't ever understand it completely, but you don't understand it as well if you do not know the language.... And one word can speak volumes."

(Interview with "Mary," July 30, 2015)

“...so culturally responsive educational leadership is...bringing together relevance, rigor, relationship to what you do in relation to culture...and making sure that as a leader you create a sense of belonging - in other words, inclusion and a sense of belonging helping your fellow Hawaiians and non-Hawaiians to achieve mastery in whatever they do, and bringing them to independence, where they can then give back."

(Interview with "Ellen," October 4, 2015)

"It's to...for us...be accountable in using our positions in the communities, so we can go out and support their learning. It should be about them - what they want to learn, how they want to learn it - and how we can work together to implement that, so we incorporate everything as much as possible - our cultural traditions, the language, the history, the practices, the values.... we need to be inclusive of like our whole entire learning community, you know, because, now it's not about us just teaching...just Hawaiian to Hawaiian kids, or Hawaiian communities. It's teaching about the Hawaiianness, ya? There's no such word, actually. But teaching that essence to everyone, so they can also experience what it's like for them to be mauli, you know, for them to be of the land, of the place, of the traditions, of the values, of the hope, of the dreams. You know what I mean? We gotta instill in all of them...this lifelong learning journey."

(Interview with "Beth," April 12, 2016)

"...so, that is very, very...important for us to realize that that kind of movement, that ability to adapt and find the best technologies, the best...methodologies to continue to transmit your knowledge, your traditional knowledge, as well as seek knowledge from, 
from the outside world, and bring it in and...make it relevant to you and yours... is a very Hawaiian thing to do.

(Interview with "Susan," November 6, 2015)

"I think it's a larger collective voice, which in my own American educational experience is opposite polar pole of my personal best. So I need to bring to the table, to the large group, that personal best, 'cause it enhances the outcomes of the, of the whole.... And so therefore, this whole thing that you're studying about culturally responsive educational leadership, the outcomes, the shaping of context, is really more group oriented than the individual leadership of it."

(Interview with "Jane," October 5, 2015)

Regarding why and how collaborative processes in the cases studied here were effective, participants acknowledged the importance of strategic recruitment of coalition group members that ensured diverse representation of constituencies with aligned interests concerning Hawaiian uplift and a shared sense of greater purpose in these efforts. Aspects of inclusion, unity and collective action described by participants highlight ways that dialogs and processes were opened up to encourage wider community involvement and influence. Thoughtful coordination allowing for trust, respect, good timing and other key intangible elements to be cultivated organically all strengthened these efforts, as well. The following quotes reflect this:

"I think the difference with Kumu Honua Mauli Ola and then later on...it was very similar in Na Honua Mauli Ola, was...it wasn't just by chance (laugh)...that these people sat at the table...There was a lot of thought that went into...who should sit at the table and what we were going to talk about... That process...usually starts with an issue. And, if enough people care about the issue, then...they start to act upon it."

(Interview with "Susan," November 6, 2015) 
“...the discussions were really important to us - and I want to say this, because they're more than just a head thing...we were really well invested, and really honing in on, on our voice of what that foundation was... in a broad sense, those underpinnings from the culture belong to everybody... I think having buy-in to the importance of the process and the goal, that people wanted to be part of something that they thought was important and good. And they had something to share. And then honoring that, and the process and the time for that to happen. "

(Interview with "Jane," October 5, 2015)

"...if not an expert, everybody was good at what they did, and we respected each other's knowledge, and valued each other's opinions...these people already knew each other, had worked with each other... came from all different fields, as you notice... so I think it was the respect we had for each other and the, the fact that we knew each other... and we respected the knowledge everybody had, in whatever area."

(Interview with "Mary," July 30, 2015)

"...the approach of many, lending many hands to the work, getting it done in a timely manner...they tell you about the ownership of the work and people then take it out. So...that was the process we used and I think that was a good process...many hands on the work makes the work lighter. So...it's like the alu like... type of... avenue that we took; alu like, everybody come together and work on this. Because everybody believed that it was necessary, so...it wasn't much convincing, everybody wanted to be a part."

(Interview with “Anne," October 7, 2015)

"...the diversity of the group. - that was the hardest thing, but that was probably the best thing....because she chose the right people from the right organizations, I mean, the buy-in, and the product was so much richer because of that."

(Interview with "Susan," November 6, 2015)

"...it was how the source of her inspiration came, and how she gathered - and this is to me something uniquely cultural, but other people will do this, too - when you first work on a project and you want to work with people, you choose the people you know you can work with, you choose the people that have the background knowledge and the cultural knowhow, so to speak, ya, to help you with this project. What I thought when she first talked about this was how she didn't just start by herself, she had the seed, she had the idea, and kind of what she wanted to do, but she brought people around herand this is a very...I'm gonna say it's a very Hawaiian thing, ya; I'm gonna gather the 
people I know that have the smarts, cultural smarts, the other kine- every kine smarts, and then I can work with that, and that's relationships...and that was how she gathered those people she trusted and she knew, had the knowledge base, and the cultural - for want of a better word - the cultural IQ to give her the input that she needed. And that Laulima thing, working together."

(Interview with “Ellen," October 4, 2015)

“...it's effective because the timing was there, and it was effective because the way we, we rolled it out, we had those discussions... We took it across the state, got input from community... that was a process of making inclusiveness, taking what we develop, getting that out to the state, having people, you know, and then getting them to endorse...we were able to get those endorsements...and then get it back out to everybody...it was a way to include...others that were responsible for the...children in public education."

(Interview with “Anne," October 7, 2015)

"Even though we hear a lot about division in the Hawaiian community, I think there's less. And definitely, I would say there's...more inclusion with everybody than in New Zealand, in terms of identity with Hawaiian things... which is really lucky for Hawaiians...you can see that by who's endorsing the Na Honua Mauli Ola."

(Interview with “John," December 6, 2015)

The element of place was acknowledged by participants as central and influential in a number of ways, which is reflected in the following quotes:

"Place is important... I always did place-based learning, because to me the places are, are the key to what our kids know and do."

(Interview with “Mary," July 30, 2015)

"You know, having traveled to the mainland, having been to Micronesia, Chuuk, Guam, Saipan...the Marshall Islands...and Pompei and those islands, and connecting with other, working with other Polynesian people, here's the thing: again, place, environment and geography are what shape people."

(Interview with “Ellen," October 4, 2015) 
"I think, even compared to American Indians, Hawaiians have a, more of a, tie to place, just because the culture is agricultural and it's...islands...And then, the real most important ethnic group in the United States, the Anglo-American ethnic group...is not highly tied to place...it seemed like history, politics...ethnicity, etcetera, all kind of coalesced...here, in an unusual way, to make being from Hawai'i...a really significant thing in people's experience."

(Interview with “John," December 6, 2015)

"The traditions and the culture was never really lost. They were embedded in families and in communities. The traditions and cultures are very much, based on the places. So, traditions, everything differs according to the place - language, dialects... It is very placed based. "

(Interview with “Mary," July 30, 2015)

"So, the relationship to place, and feeling that you are the place, in a sense, and that's kind of where that thing of the genealogies going back to the plants, and the animals, and the human beings, and the aumakua and all, like, that is a high culture codification of you being the place. But on a lower level of it is, like...this goes back to the language, but, the sense of when you're, in traditional Hawaiian culture, is that, you go someplace, you have to have a place to stay; you have to be able to go there, and so you have to have what is called the kama'aina, and so kama'aina is person who is from that place, but it also means like a host. And the malihini, or- means you're a stranger, but it also means a guest.....and that's that 'who's the leader' and 'who's the follower'. So, if you're the stranger, you gotta have somebody there who is your host; otherwise, you can't be there, because they're the one who are there..."

(Interview with “John," December 6, 2015)

"...when we talked [with teachers] about place-based and we asked them, "How did the place you come from affect, you know, how you act and what you do?" ...or... "did it make you the way you are?" this kind of thing. She says, "You know what? I never had a pilina or a relationship to the place where I grew up. But, you know what? I've been in Kohala for less than a year, and I have a pilina to this place, 'cause you guys are very place oriented." So, you know... In Hawai'i, place is of the utmost importance."

(Interview with “Mary," July 30, 2015) 
Research Question:

How are selected cases of Native Hawaiian innovations exemplifying CREL in this study significant in a global context?

\section{Themes:}

Revitalization, foundations (KHMO), frameworks (NHMO), self-determination; Hawaiian culture, language, philosophies, core values, mauli, history; Collaborative process, inclusive and pluralistic, cooperative; Systemic issues, facilitating deeper cultural understanding; CREL in Hawai'i, Hawaiian uplift, global engagement.

Prevalent themes related to this research question drew from categories pertaining to revitalization and CREL in Hawai'i, including Hawaiian uplift, self-determination, foundations (KHMO), frameworks (NHMO), language and culture revitalization, and global engagement. Ever present are themes related to Hawaiian culture and collaborative process, as well, including core values, philosophies and mauli, along with inclusive and cooperative practice. Themes speaking to challenges and problems (systemic issues, facilitating deeper cultural understanding) and related characteristics of social justice responses (Hawaiian uplift, global engagement) are also evident.

These cases represent a unique combination of system-wide social justice efforts guiding meaningful change in Native Hawaiian education. While the efforts generating these innovations were undertaken primarily for Native Hawaiians, their global significance is noted in a variety of ways throughout participant testimony. Several aspects of Hawaiian notions, perspectives and behaviors described by participants reflect global mindedness, and 
collaborations with other Indigenous cultures around the world demonstrate a global sense of responsibility embedded in local movements.

The singularly unique context and history of Hawai'i has also demanded unique solutions for unique problems - and the innovations studied here, while connected with related innovations elsewhere, represent distinctively original cases generating globally significant results. Hawai'i's role as a world leader in the global Native Language Revitalization Movement and its active presence in numerous international Indigenous-serving organizations, partnerships and coalitions reflect how localized Hawaiian efforts have been undertaken with thoughtful consideration of larger scale global context. The following quotes speak to these key considerations:

"So, that whole sense of a Mauli, or a life spirit, and that every person has one, and that they're not exactly the same, and that we're, we in particular, are focusing on having places that are using the Hawaiian genealogy as the basis for how we do things. But that Hawaiian genealogy connects to everybody in the whole world."

(Interview with “John," December 6, 2015)

"This [Na Honua Mauli Ola] is a re-affirmation, this is a codification, that's all it is. And it's also, for those who don't have this kind of mana'o, or for those who don't live thinking of these things, for them maybe it's new... that's our lens, but you can do it for any culture, I don't care where you live. These are the basic tenets of living. You know? Who doesn't want good health? Who doesn't want to have a good uh, worldview? Or who doesn't want to be smart? Who doesn't want to have self-esteem? Right? All of these things are stuff we all need to have, or need to be living."

(Interview with "Mary," July 30, 2015)

"...there is a need...there are hundreds of languages that are out there and many of them only have a few Kupuna left that can speak the language, and..." when an elder dies, a whole library dies," you know? It's gone. Volumes and volumes of knowledge is 
gone. So I think, because of the need, it's important for us to act upon it now, while we still have the resources. And that's part of our role as the leaders, but especially as growing the next generation of leaders, I think it's important."

(Interview with “Beth," April 12, 2016)

"Our processes and the way we do it is embedded in our stories; that is our critical pedagogy... That whole idea of being responsive has to do with understanding the, those cultural processes...that are tied to - for the Hawaiian sense, and I would say for a lot that I am familiar, in broader Indigenous sense - has got a historical tie to it, it has a community tie to it, it has a family tie to it, it has a genealogical tie to it... that all of these things are part of what we understand that's coming out in the stories - just how we tell the stories. "

(Interview with "Jane," October 5, 2015)

“...now we tell our stories, our big stories, on the stage...we used to just use auditoriums for our own little hula ho'ikes, but now we were telling our story, not just to, you know, auntie and uncle and cousin's neighbor, but we were telling our story to the world about our...kupuna. And, when you think, when I think about Hawaiian Education Movement, you know, that is a prime example of taking that traditional knowledge - and tradition of transmittal, which is hula - to a broader audience."

(Interview with "Susan," November 6, 2015)

"The bottom line is the culture of this place... People are coming back to it now. You know, we're finally understanding, the Hawaiian, um, the Olelo No'eau: He ali' $i$ ka 'aina ha ka kauwa ke kanaka - the land and the gods don't need us, but we need them; we can't survive without them... That might be the most important thing, and the fact that it can lead people back to not destroying this planet that we live on. And if you look at it, everybody is just now beginning to realize that fact. And, if you look at... the Alaskans, the Samis... the Ainu, the Taino of Puerto Rico, all native people...the way...they are the servant to the land... they have the same kind of mindset. They have the same lens... It doesn't matter what culture it is, it doesn't matter what language it is, the stories, are the same."

(Interview with “Mary," July 30, 2015)

“...going back to your Kumu Honua Mauli Ola example...it was written down with so many words, so many pages...and that's institutionalization of something... it built on some other institutionalization that had occurred earlier, and was more, and had the 
same idea of: can't we have this right to do this? And it seemed to be that people said yes...There was an agreement in, within the government of Hawai' $i$, and gradually in the United States and all. So... I think there's a future for this, and that...we're already working with other Native peoples who are thinking along similar lines... ours came out of first starting schools in the language and then trying to document what that was...rather than looking at education and saying, "what is a Native way to reach those things?"

(Interview with “John," December 6, 2015)

“... people thought we were gonna be real provincial, that looking at Hawaiian makes you provincial, but instead it's made us really more...worldly, I would say."

(Interview with “John," December 6, 2015)

The stories of these innovations and their implementation offer meaningful insight on CREL:

“... the Kumu Honua Mauli Ola represents how did...the older people or the Hawaiian community, Hawaiian speaking community...How did they do things? So, it was really important to have it written down for, to try and get a teacher's license thing, and, but it also took on a life of its own in the fact that...it was written using certain images...they allowed people to use those...to kind of communicate, sort of, but still based in the idea that everyone can interpret it their own way, based on their participation or knowledge of this tradition... So that made it free, but it also created a little bit more of a common vocabulary that allowed people to...use it as a structure for other things, or explain things while you're creating...it's used in schools or in other places. So, it had been done, documented, in order to create one structure, which was teacher education...approval...and to explain what we were doing in teacher education, but then it began to be used for other things, not formally, but informally, and then it could be used formally, and I guess Na Honua Mauli Ola was a, attempt, and I believe a pretty good one...even just anybody explaining it is an attempt to connect to this tradition. So that allowed a lot of other people to be part of the conversation. But, for us that were in the core group...lots of things grew out of that...loose structure to allow other structures to emerge.

(Interview with “John," December 6, 2015)

“...to really get the full effect of...a Kumu Honua Mauli-based education, each component - olelo, ike ku'una...lawena, pili, uhane - they all have to...be working together; you cannot put more weight on one than the other... there has to be equity amongst those key areas for it to be successful. And, I think that, that's the work that 
still needs to happen...if they really want to experience that level of success in today's Native Hawaiian education movement, then you need to develop equity amongst those things. And that's gonna be hard... And that was the whole purpose of Na Honua Mauli Ola, was to give some kind of insight to... agencies and organizations, preferably educational entities... a part of the equation - but you gotta come up with the other four variables, as your own. And...that's not everybody's used to, to coming up with their own variables...they want the template, and they just wanna bang that thing out, you know. And they think one all be the same, and it's not. It's not...there are so many other things that are unspoken, that have to be learned - they're learned behaviors. They're learned practices... that's a part of the process that I think many people don't get, is in implementation. And I wish they would be more confident in...and cognizant of the work they do, because if you're cognizant of the work you do, you paying attention, you're gonna start to notice the trends. You're gonna start to notice what works for you and what doesn't work for you....and you start to deduce the variables. And then you learn how to play with the equation."

(Interview with "Susan," November 6, 2015)

That's what the Kumu Honua Mauli Ola...is for us, is a documentation of the philosophy. Now how that comes out in the implementation... is for the interpretation of...our teachers, our families, you know, and as we continue... you go back and you look at that document, and... you can point to that as...the philosophy for the movement to revitalize Hawaiian, and it's embedded in all those, you know, the seen and unseen on that paper too.

(Interview with “Anne," October 7, 2015)

\section{Research Question:}

In this case study of Native Hawaiian innovations, what significant implications are apparent in relation to CREL efforts and resonant movements elsewhere in the world?

Themes:

Systemic issues, bureaucracy, facilitating deeper cultural understanding; Collaborative, culturally responsive, inclusive, unity, cooperation; Revitalization, self-determination, CREL, Hawaiian uplift, global engagement; Hawaiian culture, language, philosophies, core values, mauli, history. 
Themes related to the host of issues, challenges and problems faced in these CREL efforts - including systemic issues, bureaucracy and facilitating deeper cultural understanding are prevalent in relation to this research question. Themes related to collaborative process also speak to aspects of responsive practice for developing solutions. Additionally, themes of global engagement and Hawaiian uplift reflect social justice oriented purposes.

Participant stories recounting how these efforts evolved reflect the adaptiveness and resilience of many people involved. Over the course of decades, opportunities for progress were cultivated and seized through system-wide collaboration among core members of movements represented across organizations dedicated to culturally responsive Native Hawaiian education through language and culture revitalization. The stories of these innovative cases reflect how individual efforts were thoughtfully aligned and cooperatively coordinated with larger group efforts all guided by a unifying values-driven mission of developing a shared foundation, framework and strategies for Hawaiian uplift. Much can be gleaned from participants' explanations of significant challenges:

"...the biggest challenge is the system that they work in and the leadership of that system, whether they're willing to...look outside of their normal perspective... I think one of...the difficult things...is of course being cohesive - especially in education, you want to, you want to continually build upon the knowledge that is, and the skills that are developed, right? ...as an administrator, I understand the importance of having a systemic approach...to curriculum and pedagogy. When one individual...tries to step outside of that approach...it's viewed by some as a challenge... challenging authority... an admittance of failure...it can be very intimidating. And that's why a lot of teachers don't try. Even some that I think are very culturally responsive in their day-to-day life, outside of work are bound by the systems that they work in. So, I mean, hats off to the ones who find one way to worm it in and slowly infiltrate the system they work in." (Interview with "Susan," November 6, 2015) 
"One of the biggest challenges is...the bureaucracy of the state and any other system. The bureaucracy that tells you, 'you gotta follow these rules, and you cannot do that,' and whatever...those are significant, and unless you are...dogged enough...to overcome them, they can seem like they are insurmountable. But like I told you the last time, like Mary Correa's T-shirts say: 'If can, can. If no can, how can?'... So... it depends on how tenacious you are...to me the bureaucracy is the biggest challenge today; the bureaucracy of all of this - no matter what system you work in."

(Interview with "Mary," July 30, 2015)

"We've gotten to a point.... where we have some pretty influential people...interested and excited about...the strategies and the pedagogy of successful Native Hawaiian education programs. And then you have some people who are, you know, at ground zero, in the classrooms, who come to all our trainings, and maybe were former teachers in our program or participants in our program, trying these things out. But there is this big expanse of ocean in the middle (laugh)...and...finding the right ways, pathways, strategies, methods, to...close that gap.... that's a big challenge."

(Interview with "Susan," November 6, 2015)

Participants describe key operational considerations, as well, including personal

investment, dedication to a greater purpose, and clear communication. The value of allowance, anticipation and thoughtful intention are also acknowledged as important in collaborations.

Descriptions of working modes are rendered as ways of living, involving deep awareness of (and active connection with) cultural context. The following quotes reflect this:

"...we need to be okay with going into some different directions, because the process is showing...The process tells you all the signs; it tells you when to veer to the right and left, if you're paying attention to it. And that's part of being responsive. But you have to...know how to read those signs. And so you need to know enough about the culture to be able to be responsive enough to read those signs."

(Interview with "Jane," October 5, 2015) 
“...when you orchestrate the madness, there also has to be enough room - you can't plan everything, you cannot plan everything - you have to have enough space for the faith card. And...some things are gonna happen in the moment...you need to prepare yourself for that, and have...extra trick cards in your pocket, you know, and be ready to play that hand - you gotta be ready to play the hand, whatever is dealt...my husband and I call it the Kahuna role. (laugh)... everybody has a function, everybody potentially could have a role to play in the project, but only the Kahuna knows who fits best where and how to utilize them, and also how to groom them to achieve a new level of skill...no more too many good Kahunas out there nowadays (laugh)... It's not always by telling that you illicit the best product."

(Interview with "Susan," November 6, 2015)

“...we worked, I mean, we worked...we were always meeting, and...reflecting, and...planning and....we were even wanana, you know...anticipating... kind of seeing what the signs were, and being able to, I don't know, predict what might be happening...it took each of our Board Members to be intimately involved with their school on their island...they had to be involved in... their local communities... as we grew...So that leadership...Native Hawaiian leadership, what does it take, you know? It is really...dedicated folks...I see that as really a strength of the movement, because we had such a dedicated...leadership that wasn't afraid to...pull all nighters

and...weekends...there wasn't, 'oh I can't,' or, 'this weekend we have,' you know...'cause the work was so important."

(Interview with "Anne," October 7, 2015)

“...you have to want to, to learn or to participate, and...there's a term that's koho 'ia; you do not choose to do this work, you are chosen... And for so many, that is true. But you also have to want to do it... So, it's either the desire to be that leader or to make that change, or the fact that you feel you don't have a choice, but you have to do it... both of those are to me the most important thing about the leadership."

(Interview with "Mary," July 30, 2015)

"...the better you can articulate to others, if you think you have something good, that other people will appreciate, and that you can speak to them, it's like a bridge...a way to explain things to others...that's important, to be able to do."

(Interview with “John," December 6, 2015) 
“...it's that knowledge, your cultural IQ, if you will, and your knowledge base from the Western side, ya, and always coming into a group with that. When they walk in, all of these people seem to have a joy and a passion for what they are doing, and they want to share it with you in the most humble way they can."

(Interview with "Ellen," October 4, 2015)

"...a fire had to be lit. We gotta do that as leaders. We're gonna have to be the ones to go out and tell them why it's important for us to learn about our language - any language - to learn about our history, to learn about our traditions, so those can stay alive, so that when we pass, the next generation can continue to fulfill that leadership responsibility. If we don't grow our leaders in the culture and the language, then who's gonna be around to teach them once we are gone? Because we are doing all of this for them, right?"

(Interview with “Beth," April 12, 2016)

Participants' descriptions of the CREL cases studied here reflect their identity-driven nature and collective purpose in encouraging self-determination and Hawaiian uplift, as the following quotes demonstrate:

"Na Honua Mauli Ola provides an articulation for a contemporary setting. But, they resonate best practices and best understandings that come from a particular culture the Hawaiian culture ... that have been expressed through practices that are many generations tried and tweaked... I think what Na Honua Mauli Ola does is it revitalizes all of that good stuff that we come from. And isn't that a really good place to re-honor your own sense of yourself? You- yourself come from that greatness of that culture. So, there are a lot of things that call people to the table, from understanding that. Maybe part of the challenge is, how do you contextualize that, that moves people to come around the table in a certain way?"

(Interview with "Jane," October 5, 2015)

“...they are actually returning to traditions, or returning to traditional ways... these are all old ways, and I don't think innovative in the sense that you're doing something new... but it's innovative in the sense that you're bringing back prior knowledge and reintroducing it to people who may, not... you know, have knowledge of it." 
(Interview with “Mary," July 30, 2015)

"We're taking what's old and finding relevance. We're not making it new. We're just taking what's old and finding the relevant fit in today's world."

(Interview with "Susan," November 6, 2015)

"So...I think...we've put out there what...is all intended as pathways to...increase, you know, student participation, family participation in the education of their...children...it gives them...that relationship building, for students and families to have, to find...their important role in their own self-determination; as a student, I'm determined, you know, this is my own self-determination... They will say you can always lead the horse to the water, you cannot make 'em drink the water. (laugh) So... if the students know that, right? They wind up drink."

(Interview with "Anne," October 7, 2015)

“...if people have an identity, a group of people...education can be valuably developed through that. And...part of it is also that people have the right to determine what they want for their education...or that they kind of stand up for want they believe is theirs that it's not bad. I think that's the most basic thing."

(Interview with “John," December 6, 2015)

"So, I think...for us to regain the language and the culture that was almost lost is really, really important, and being able to put that down on paper, and to publish in a book, and to help with the educating of our own kids is part of that innovation that those guidelines have provided for us, and the philosophy. We need that, because a lot of families are not raising with Kupuna anymore, and they don't have elders in their lives that can help direct them, whether they're Hawaiian or not. And, so, people are searching, they're searching, and these things can really help to ground us and focus on the priorities that is important."

(Interview with “Beth," April 12, 2016)

"the most important thing to understand is that you have to broaden that education, like in Na Honua Mauli Ola, we have to strengthen our families. This is what I see with our Native Hawaiian children who come from poverty. Strengthen families...and address the needs of poverty in our community...by addressing poverty, educational needs...jobs...strengthening your communities, ya?" 
(Interview with "Ellen," October 4, 2015)

"...if we believe that our words are powerful, these are all gonna be a part of the development... that's Native Hawaiian education, and that's Native Hawaiian leadership, because you are empowering, you are part of, of that development of, you know, the next leaders. But, by feeding these words of encouragement, by feeding the words of empowerment... this is how you are framing the world for this next generation for them to then have... that responsibility to carry it on, and all of...those...things that go hand in hand with, you know, with who we are - got lots and lots of, of things that are embedded."

(Interview with “Anne," October 7, 2015)

Participants also describe their personal motivations and the inclusive nature of their work in a collective context, as reflected in the following quotes:

"I want to make sure...the discussions and...the training of our kids, and how they see the world...you just want them to be...curious about everything...that's around them...you know, seek...know how to use the technology...to advance, and really to highlight....what it means to be, you know, educated from your own language and culture in its homeland."

(Interview with “Anne," October 7, 2015)

"I realized that...many teachers, their hands and feet were still bound by...a system- a Western system of education that didn't understand what Hawaiian language immersion - which is what we started as; we called each other Hawaiian language immersion program...today we call ourselves Hawaiian medium...but - it still had, still they was in chains, and I thought, "wow, how can we break those chains," you know, how do we get ourselves to that point where we, we get free thinking Hawaiians again, that are...not ashamed of their history, of their cultural practices...I really saw Punana Leo as the vehicle to help our Hawaiian families, young Hawaiian families reestablish traditional...philosophies of child rearing. And...when you think about that word education in a traditional Hawaiian sense...education happens in the home, and it goes far beyond academic pursuits...it's a really holistic type of education."

(Interview with “Susan," November 6, 2015) 
"The Native Hawaiian Education Movement is a movement to revitalize Hawaiian...that's the innovation...that's where it takes off, that's where it's defined as unique, it belongs to this place, it's... what everybody is...and it's for everyone....it's about that thing called the Hawaiian language and that thing called the culture that belong to that language and the people that belong to that language, which is more than just the Native Hawaiian."

(Interview with “Anne," October 7, 2015)

"...if we can share whatever worked for us with others, as well, that would help them build a stronger foundation, and maybe faster. It's not gonna take them as many years to go through a lot of the processes. And it's not that we know and we have all the answers. I think we can share with you what is valuable when we share what has not worked for us. That is what is important. A lot of the things that haven't worked for us, we can share, because then they can avoid having to struggle through those same kind of challenges, and move on to the next step. So that could really be helpful to others that we could share, you know, out there in the world, 'cause that is really, really important. There is a need, in all of our cultures, all of our communities, so if we can actually help each other, I think we all can move together."

(Interview with “Beth," April 12, 2016)

Throughout participant testimony, suggestions are offered for those developing their own authentic understanding of CREL in other contexts. Generally speaking, deeper understandings of place and shared visions of identity can appropriately guide localized collaborations driven by unifying missions aspiring to be culturally responsive. Every context is unique, in terms of issues that will mobilize collective action, amounts and types of available resources (especially human resources), the nature of structural systems that must be navigated, and so on. Successful alignment and coordination of collective CREL efforts relies on clear articulation, framing and active representation of foundational core values, purposes and strategy, thereby encouraging intended outcomes through cultivating relational understandings of CREL in a local context. In any situation, harnessing the collective power of people for a 
common purpose is fueled by clearer shared awareness of the place, its people and their unique history. 


\author{
CHAPTER V \\ DISCUSSION, CONCLUSIONS, IMPLICATIONS AND \\ RECOMMENDATIONS FOR FUTURE RESEARCH
}

\title{
Discussion
}

Using a case study approach, this study examines - through qualitative analyses conducted from a non-Indigenous perspective - the evolution and impact of specific Indigenous innovations exemplifying CREL in Hawai'i (the NHMO Guidelines, NHMO Pathways and KHMO Philosophy Statement), based on data and interview testimony obtained directly from education professionals actively involved in their creation and implementation. A three-phase interview process is conducted with seven study participants - combining survey-based, minimally structured/dialogic and semi-structured methods - documenting first-hand accounts of these innovative CREL process and outcomes, while exploring their local and global significance - and addressing the following core research questions of this study:

- What is essential to understand about CREL in the unique context of Hawai'i, according to participants in this study?

- How are selected cases of Native Hawaiian innovations exemplifying CREL in this study significant in a global context?

- In this case study of Native Hawaiian innovations, what significant implications are apparent in relation to CREL efforts and resonant movements elsewhere in the world? Analysis of data involved a three-phase manual coding and memoing process using audio recordings and verbatim transcripts of interviews in combination. A composite transformative leadership centered theoretical framework adapted from the work of Shields 
$(2003,2004,2010)$ and Furman and Shields (2005) provides appropriate language and concepts used throughout coding and analyses and, generally speaking, is used as a lens for identifying, mapping and organizing key elements and themes reflected in interview data in relation to CREL and the core research questions of this study. A transformative leadership framework is used to enable appropriate analysis of these social justice efforts. The conceptual framework used to summarize key themes from this data (see p. 61) is also adapted from Furman and Shields (2005).

The triple-case focus of this research represents an evolving series of foundational system-wide CREL development efforts spanning decades and resulting in historic achievements striving for collective Hawaiian uplift and shared understanding of Hawaiian philosophies, core vales, traditions and mauli, or life force. Participants in this study include core members of movements in Hawaiian language and culture revitalization for Native Hawaiian education, leaders of sponsoring organizations for the cases studied here, and cocreators of the innovations themselves, whose ongoing collaboration across organizational domains, educational levels and structural sectors continues to yield fundamental change addressing persistent inequities and systemic issues in this unique context (Kawai'ae'a and Wilson, 2007; Rawlins, 2011). The stories of Indigenous innovation and articulations of CREL documented in this research offer profound insight and guidance for social justice oriented education professionals everywhere.

The systems-level scope of this study allowed for clearer conceptualization of how interorganizational collaboration developed over time throughout the unique structural systems of 
the Hawaiian context - all driven by the tireless work of dedicated individuals and their collaborative relationships. The review of literature conducted for this study allowed for including more diverse conceptual language and varied articulations of CREL elements and characteristics from different standpoints in the research process. The theoretical framework adapted from transformative leadership literature and applied in data analyses allowed for deeper appreciation of the social justice nature of these CREL efforts in operational terms within the unique Hawaiian context. The situated methodological approach of this study allowed for more comprehensive first-hand understandings of local strategy and the global significance of these collective CREL efforts. Most importantly, rich stories of the CREL cases studied here are documented from core participants in movements for Hawaiian uplift.

Regarding the core research question of what participants consider essential to understand about CREL in Hawai'i, prevalent themes include the following:

Identity, geneology, self-awareness, relationships, family, homeland, local knowledge; Hawaiian culture, language, traditions, philosophies, core values, mauli, history; Culturally responsive, collaborative, resourceful, inclusive, unity, cooperation; Revitalization, foundations (KHMO), frameworks (NHMO), self-determination, uplift.

To truly understand CREL in Hawai'i, developing one's own deeper understanding of the Hawaiian cultural context is unanimously acknowledged by participants as paramount. The degree of awareness and depth of understanding one can achieve of Hawaiian language and history, one's own identity, sense of (and relationship with) place, genealogy, and local knowledge - including that which is unspoken - all influence the diverse shared capacity of the groups one inhabits in Hawai'i, while encouraging a more familial relational dynamic and more naturally collaborative determination of coordinated individual roles and responsibilities, which 
is the traditional Hawaiian way. It starts with knowing who you are, where you're from, and what you intend to do. In this study, through application of a unique transformative leadership focused theoretical lens (Shields, 2010; Furman and Shields, 2005) in data analyses, the transformative nature of Native Hawaiian CREL in these cases is demonstrated through their unity and inclusiveness, their deep respect for diversity and plurality, their social justice missions, and their global-minded community-oriented approach, among other characteristics reflecting transformative tenets (Shields, 2013).

Regarding the core research question of how the cases of innovation studied here are significant in a global context, prevalent themes include the following:

Revitalization, foundations (KHMO), frameworks (NHMO), self-determination; Hawaiian culture, language, philosophies, core values, mauli, history; Collaborative process, inclusive and pluralistic, cooperative; Systemic issues, facilitating deeper cultural understanding; CREL in Hawai'i, Hawaiian uplift, global engagement.

The global nature of these localized innovations is noteworthy, highlighting the significance of established international relationships. For example, participants acknowledge that the Te Aho Matua effort of the Maori served as an influence for the Kumu Honua Mauli Ola effort later undertaken by Hawaiians; years later, the Na Honua Mauli Ola Guidelines were based on a template from the Alaska Standards for Culturally Responsive Schools (Native Hawaiian Education Council, 2002). These innovations serve as a foundation and operational framework for the UHH-CHL, which, among other efforts, is actively engaged in developing international collaborative models of Indigenous education and Indigenous teacher education (Galla, Kawai’ae’a \& Nicholas, 2014), while maintaining a strong leadership presence in the 
global Native Language Revitalization Movement (Rawlins, 2011). Additionally, the global significance of these cases is demonstrated through other ongoing international partnerships and projects involving the sponsoring organizations of these efforts - including the $\mathrm{UHH}-\mathrm{CHL}$, APL and NHEC. As participants acknowledge, localized approaches toward similar types of foundational CREL efforts in other contexts can entail a number of human aspects and cultural elements that occur universally across situations, though they manifest uniquely in each instance. Values-driven discussion, identity-driven approaches, and collectively unified strategy can be developed for other contexts using the types of localized, culture-based and place-based methods studied here.

Regarding the core research question of what significant implications are apparent in relation to CREL efforts elsewhere, prevalent themes include the following:

Systemic issues, bureaucracy, facilitating deeper cultural understanding; Collaborative, culturally responsive, inclusive, unity, cooperation; Revitalization, self-determination, CREL, Hawaiian uplift, global engagement; Hawaiian culture, language, philosophies, core values, mauli, history.

Persistent challenges illuminate key considerations in these cases. Participants acknowledge that, in any context, developing an authentic understanding of CREL involves developing deeper collective understandings of place and shared visions of identity that can appropriately guide localized collaborations driven by unifying missions aspiring to be culturally responsive. Every context is unique, in terms of issues that will mobilize collective action, amounts and types of available resources (especially human resources), the nature of structural systems that must be navigated, and so on. Successful alignment and coordination of collective CREL efforts relies on clear articulation, framing and active representation of foundational core 
values, purposes and strategy, thereby encouraging intended outcomes through cultivating relational understandings of CREL in a local context. In any situation, harnessing the collective power of people for a common purpose is fueled by clearer shared awareness of the place, its people and their unique history, according to study participants.

At the conclusion of this study, despite restructuring, cutbacks and reduced funding resulting from ESEA reauthorization and budget constraints at the state and federal level, Native Hawaiian education efforts continue, as before, through greater reliance on community support; for example, while the structure and budget of the NHEC has been condensed through legislative changes, local community projects and Island Council activities continue through greater reliance on volunteers - and, new culture-based assessment and evaluation tools based on the NHMO framework are being utilized by NHEA grantees (personal communication, 2015); as multiple participants acknowledge in this study, despite funding losses, collaborative efforts among Native Hawaiian serving organizations have successfully embedded culture-based priorities in statewide educational policies and strategic plans. As collaborations between Native Hawaiian serving organizations and educational institutions are increasingly aligned and coordinated over time, expanding shared cultural understanding, clarifying cultural identity and growing collective voice throughout the Hawaiian community will all encourage greater degrees of unified action to develop across stakeholder groups. The growing strength of the Native Hawaiian education movement will continue to make the Hawaiian education system as a whole even more unique through new policies, programs and partnerships driving system-wide structural changes. Beyond the growing local impact of these continuing CREL efforts, their 
global influence will also evolve through expanding international collaborations. Shared progress will be increasingly influenced by a growing number of active participants who endeavor to address persistent challenges in movements for Indigenous uplift worldwide.

\section{Conclusions}

This study answers calls from multiple domains in the global research communityincluding calls for more involved social justice oriented research and practice in educational leadership and administration (Furman \& Shields, 2005; Shields, 2010, 2013), more meaningfully unique methodological approaches toward qualitative inquiry (Denzin, 2010; Lincoln, 2010), and more cooperative approaches toward cross-cultural education research (Kawagley \& Barnhardt, 1998; Galla, Kawai'ae‘a \& Nicholas, 2014), among others - through conducting a thoughtfully designed and simply structured case study of Indigenous CREL innovations, including documenting first-hand accounts of these exemplary efforts. The rich data collected from participants speaks to the nature of CREL and the global significance of their localized efforts in the singularly unique education system and cultural context of Hawai'i. Their stories also offer profound insight and guidance for education professionals seeking to be transformative and culturally responsive in their approaches toward understanding leadership.

As participants acknowledge, those who choose (or are chosen for) this type of CREL work can face daunting cognitive, communicative and relational challenges while striving to be healthy agents of meaningful change, but those who persevere can find far greater strength in numbers through the synergy of transformative collaboration. Clearer shared understandings 
of core values, collective identity and unifying missions can naturally propel and guide CREL efforts accordingly, as demonstrated in the cases studied here, and according to study participants. For example, the thoughtfully strategic recruitment of coalition group members in these cases enabled diversity of perspectives, varied expertise and broad stakeholder representation, while allowing for participants' familiarity with each other to encourage a more familial working dynamic and safe space for free and open discussion. Large and small group processes in these cases - for Kumu Honua Mauli Ola, conducted solely in Hawaiian language allowed for cooperative task sharing aligned with participants' respective backgrounds, skill sets and core areas of personal interest, in a manner described by participants as "organic."

Organizationally speaking, the UHH-CHL served as a crucial hub for connecting collaborative networks throughout the Hawaiian education system and abroad. The Kahuawaiola Indigenous Teacher Education Program provided the impetus for documenting the KHMO Philosophy and, later, development of the NHMO Guidelines and Pathways documents to serve as a foundation and framework for their culturally responsive educational practice. Now a wide variety of programs, schools and organizations across the Hawaiian Islands (including the Hawai'i Department of Education) utilize this foundation and framework for guiding their efforts in alignment with movements to revitalize Hawaiian language and culture to support Hawaiian uplift, as participants acknowledge in this study.

The organizational partners of the UHH-CHL in these cases, particularly the NHEC and APL, are also noteworthy in their character and respective roles in these efforts. The NHEC (an independent agency generated through NHEA federal legislation) provided unique connections 
to resources, venues and collaborators across the Hawaiian education system, as did the APL (a unique community-oriented nonprofit Hawaiian medium education network). These partnerships - including all of the additional collaborators involved in the endorsement, adoption and implementation of these efforts - and their combined influence, represent a crucial part of what makes these CREL efforts powerful. Through cultivating increasingly coordinated inter-organizational collaborations across the system that are aligned with (and invested in) a shared CREL mission of revitalization, all core constituencies and stakeholder groups can be represented and actively involved in generating meaningful changes locally for collective benefit.

What seems essential for arriving at deeper operational understandings of CREL, generally speaking, is a holistic exploration of the human dimensions of organizations and communities to achieve more comprehensive functional awareness of local thinking, behavior and needs. Cultivating knowledge of shared identity, relational connections and unifying purposes can be essential for increasing collective CREL capacity in a local context. In this way, leadership in any circumstance can be about all of us, and can involve everyone - together, we must make it ours and develop our own unique roles in collaboratively ensuring shared progress for the common good.

Implications

There are broad implications for research and practice that every reader can take from this study, and highlights speaking to operational and organizational understandings of CREL 
are the primary focus here. Bearing in mind the alignment and parallels represented in literature reviewed previously (including calls echoed across domains for developing new understandings of leadership practice enabling healthier and more meaningful outcomes), the collective nature of CREL is clearly demonstrated in the triple-case focus of innovations studied here; everyone involved determines how these CREL efforts work, and how well they work. Participants acknowledge their shared collective responsibility in these CREL efforts and the importance of facing challenges collaboratively, adaptively and resiliently for the good of all. In these cases, according to participants, the process of growing collective capacity for CREL involved developing foundations and frameworks for facilitating deeper fundamental cultural understanding across diverse stakeholder groups and varied circumstances. Inclusivity, deep respect for diversity and pluralistic perspectives allowed for identifying shared core values, cultivating shared senses of identity and formulating unified globally-minded social justice missions through localized approaches toward CREL based on local cultural foundations, traditions and history. In this vein, the preservation and revitalization of ancient knowledge systems offered profound guidance for contemporary strategy in Native Hawaiian education, as has been the case in other Indigenous contexts, as well - including Alaska and New Zealand.

CREL inquiry, whether for theoretical or practical purposes, challenges us to truly know how we know what we know, develop deeper understandings of our epistemological foundations and strengthen our senses of self, our communities and our collective needs, among other things, in order to properly serve them. Whether labeled transformative, culturally responsive or otherwise, the type of collective leadership demonstrated in the cases 
studied here requires each participant to summon great courage, and often take great personal risk, as they strive to be fully invested in the greater purposes of their unified CREL missions. The active core of this practice involves a fundamental re-humanization process pursued uniquely by each individual that, over time and through socio-cultural means, can become increasingly embedded in the operational nature and identities of the organizations they inhabit and throughout the larger landscape of related structural systems. In this way, CREL represents an ultimate test of our collective human capacity to know who we are, be who we are and do what we must do, for everyone's sake.

\section{Recommendations for Future Research}

This study represents the equivalent of a pilot effort that I hope will lead to larger scale efforts of this sort exploring CREL strategy further in Hawai' $i$ and across other cultures and contexts through comparative international studies. The movements explored here continue to evolve and chart progress, and countless stories of CREL innovation have yet to be recorded, so I hope to continue documenting them in the years to come. I also hope to inspire others to pursue their own unique study of CREL, along with the preservation of oral histories and the celebration of localized innovations growing around the world. More qualitative systems-level analyses of leadership in education are recommended for gaining clearer understandings of systemic issues, core challenges and collaborative solutions. Although I chose to use a nonIndigenous theoretical framework for this study as a non-Indigenous researcher, I hope that others will acknowledge the value of utilizing the foundation and framework studied here as a 
powerful theoretical lens for CREL analyses conducted by Indigenous researchers in Hawai'i. Developing a working understanding of CREL involves a personal quest for deeply collaborative learning, and I encourage all social justice oriented education professionals to forge their own unique paths in pursuit of this meaningful work.

The interview data documented in this study represents part of a wider evolving dialog concerning CREL efforts unfolding in the unique Hawaiian context. Researchers and practitioners from various disciplines can benefit from engaging this dialog directly and developing deeper understandings of how these CREL efforts are making meaningful change for historically underserved students. The topic of CREL offers numerous opportunities for qualitative researchers to explore uncharted territory and illuminate significant considerations for education professionals seeking to be more culturally responsive in their work, and this type of inquiry is highly recommended wherever it can occur meaningfully.

Although I began this project as an outsider relative to the Native Hawaiian Education Movement, through the process of this effort I found ways to get involved in the communities where I conducted research, develop my own unique role as an active resident stakeholder, and contribute to these CREL efforts as a documentarian through this doctoral study. Family matters pulled me back to the mainland, but after living in East Hawai'i for five years, my approach to life and work continues to be influenced greatly, even in very different places, by how I learned to live there. My own working definition of CREL is: "collaboratively coordinated leadership of a living mission for the good of all, in deep connection with the place and the culture of its people" - and my experience in this research helped me understand far more 
broadly and deeply how meaningful this transformative work can be for everyone involved. I encourage you to deepen your own understanding of this, as well. 


\section{REFERENCES}

Adler, P. \& Jermier, J. (2005). Developing a field with more soul: Standpoint theory and public policy research for management scholars. Academy of Management Journal, 48(6), 941944.

'Aha Punana Leo, Inc. and Ke Haka 'Ula O Ke'elikolani. (2009). Kumu Nohua Mauli Ola: A Native Hawaiian Educational Philosophy Statement. Hilo, HI: University of Hawaii at Hilo.

Alcoff, L. M. (1996). Real knowing: New versions of coherence theory. Ithica, NY: Cornell University Press.

Anderson, G. L. (2004). William Foster's legacy: Learning from the past and reconstructing the future. Educational Administration Quarterly, (40), 240-258.

Argyris, C. \& Schon D. A. (1974). Theory in practice: Increasing professional effectiveness. San Francisco: Jossey-Bass.

Assembly of Alaska Native Educators. (1998). Alaska standards for culturally-responsive schools. Anchorage: Alaska Native Knowledge Network.

Auerbach, S. (2009). Walking the walk: Portraits in leadership for family engagement in urban schools. The School Community Journal, 19(1), 9-31.

Barnhardt, R. \& Kawagley, A. O. (2005). Indigenous knowledge systems and Alaska Native ways of knowing. Anthropology and Education Quarterly, 36(1), 8-23.

Battiste, M. (2001). Decolonizing the university: Ethical guidelines for research involving indigenous populations. In Findlay \& Bidwell, P. (Eds.) Pursuing academic freedom: Free and fearless? (pp. 190-203). Saskatoon, Saskatchewan, Canada: Purich Press. 
Battiste, M. (2002). Indigenous knowledge and pedagogy in First Nations education: A literature review with recommendations. Ottawa, Ontario, Canada: Indian and Northern Affairs.

Bean, T. \& Zulich, J. (1992). Education in Hawaii: Balancing equity and progress. In Smith, Z. and Pratt, R. (Eds.) Politics and public policy in Hawaii (215-228). Albany, NY: State University of New York Press.

Benham, M. \& Heck, R. (1998). Culture and educational policy in Hawaii: The silencing of native voices. Mahwah, NJ: Lawrence Erlbaum Associates.

Berg, B. L. (2009). Qualitative research methods for the social sciences. Boston: Pearson.

Bloom, C. M. \& Erlandson, D. A. (2003). African American women principals in urban schools: Realities, (re)constructions, and resolutions. Educational Administration Quarterly, 39(3), 339-369.

Bolman, L. G. \& Deal, T. E. (2008). Reframing organizations: Artistry, choice and leadership. San Francisco: Jossey-Bass.

Bolman, L. G. \& Gallos, J. V. (2011) Reframing academic leadership. San Francisco: Jossey-Bass. Borofsky, R., Barth, F., Shweder, R., Rodseth, L., \& Stoltzenberg, N. (2001). A conversation about culture. American Anthropologist, 103(2), 432-446.

Boyles, D. (2009). Considering Lorraine Code's ecological thinking and standpoint epistemology: A theory of knowledge for agentic knowing in schools? Philosophical Studies in Education, 40, 125-137.

Brown, K. M. (2004). Leadership for social justice and equity: Weaving a transformative framework and pedagogy. Educational Administration Quarterly, 40(1), 77-108. 
Brown, K. M. (2006). Leadership for social justice and equity: Evaluating a transformative framework and andragogy. Educational Administration Quarterly, 42(5), 700-745.

Burbules, N. \& Torres, C. (Eds.). (2000). Globalization and education: Critical perspectives. New York: Routledge.

Burger, D., Mauricio, R. \& Ryan, J. (2007). English language proficiency assessment in the Pacific region. Washington, D.C.: U.S. Department of Education, Regional Educational Laboratory Pacific Region.

Bustamante, R. M., Nelson, J. A., \& Onwuegbuzie, A. J. (2009). Assessing schoolwide cultural competence: Implications for school leadership preparation. Educational Administration Quarterly, 45(5), 793-827.

Casey, C. (2006). Contested rationalities, contested organizations: Feminist and postmodern visions. Journal of Organizational Change Management, 17(3), 302-314.

Castagno, A. E. \& Brayboy, B. M. J. (2008). Culturally responsive schooling for indigenous youth: A review of the literature. Review of Educational Research, 78(4), 941-993.

Clayman, S. E. \& Gill, V. T. (2004). Conversation analysis. In Hardy, M. and Bryman, A. (Eds.) Handbook of data analysis. Thousand Oaks, CA: Sage.

Code, L. (2006). Ecological thinking: The politics of epistemic location. Oxford, UK: Oxford University Press.

Cooper, C. W. (2009). Performing cultural work in demographically changing schools: Implications for expanding transformative leadership frameworks. Educational Administration Quarterly, 45(5), 694-724. 
Crow, G. M. (2007). The complex landscape of successful principal practices: An international perspective. International Studies in Educational Administration, 35(3), 67-74.

Demmert, W. \& Towner, J. (2003). A review of the research literature on the influence of culturally based education on the academic performance of Native American students. Portland, OR: Northwest Regional Education Lab.

Denzin, N. K. (2010). Moments, mixed methods, and paradigm dialogs. Qualitative Inquiry, $16(6), 419-427$

Denzin, N. K. \& Lincoln, Y. S. (2005). Introduction: The discipline and practice of qualitative research. In N. K. Denzin \& Y. S. Lincoln (Eds.), The SAGE Handbook of Qualitative Research (3 ${ }^{\text {rd }}$ ed.) (pp. 1-32). Thousand Oaks, CA: Sage.

Dewey, J. (1916). Democracy and education. New York: Macmillan.

Dillard, C. (1995). Leading with her life: An African American feminist (re)interpretation of leadership for an urban high school principal. Educational Administration Quarterly, 31(4), 539-563.

Drath, (2001). The deep blue sea: Rethinking the source of leadership. San Francisco: JosseyBass.

Drucker, P. F. (2001). The essential Drucker. New York: HarperCollins.

Firestone, W. A. and Riehl, C., Eds. (2005) A new research agenda in educational leadership. New York: Teachers College Press.

Foster, W. P. (2004). The decline of the local: A challenge to educational leadership. Educational Administration Quarterly, (40), 176-191. 
Freire, P. (2000). Pedagogy of the oppressed ( $30^{\text {th }}$ anniversary ed.). New York: Continuum.

Furman, G. C. (2010). Social justice leadership as praxis: Developing capacities through preparation programs. Educational Administration Quarterly, 48(2), 191-229.

Furman, G. C. and Shields, C. M. (2005). How can educational leaders promote and support social justice and democratic community in schools? In Firestone, W. A. and Riehl, C., Eds. (2005) A new research agenda in educational leadership. New York: Teachers College Press.

Galla, C. K., Kawai'ae‘a, K. \& Nicholas, S. E. (2014). Carrying the torch forward: Indigenous academics building capacity through an international collaborative model. Canadian Journal of Education, 37(1), 193-217.

Gee, J. P., Michaels, S. and O’Connor, M. C. (1992). Discourse Anaysis. In M. D. LeCompte, W. L. Milroy and J. Preissle (Eds.) The Handbook of Qualitative Research in Education. San Diego: Academic Press. 227-291.

Geertz, C. (1973). The interpretation of cultures. New York: Basic Books.

Geertz, C. (1983). Local knowledge: Further essays in interpretive anthropology. New York: Basic Books.

Greckhamer, T., Koro-Ljungberg, M., Cilesiz, S., \& Hayes, S. (2008). Demystifying interdisciplinary qualitative research. Qualitative Inquiry, 14(2), 307-331.

Greenleaf, R. K. \& Spears, L. C. (Ed.). (2002). Servant leadership: A journey into the nature of legitimate power and greatness. New York: Paulist Press. 
Grogan, M. \& Shakeshaft, C. (2011). Women and educational leadership. San Francisco: JosseyBass.

Guba, E. G. \& Lincoln Y. S. (2005). Paradigmatic controversies, contradictions, and emerging confluences. In N. K. Denzin \& Y. S. Lincoln (Eds.), The SAGE Handbook of Qualitative Research ( $3^{\text {rd }}$ ed.) (pp. 191-216). Thousand Oaks, CA: Sage.

Gunter, H.M. (2016). An intellectual history of school leadership practice and research. New York: Bloomsbury.

Hampton, E. (1988). Toward a redefinition of American Indian/Alaska Native education. Unpublished doctoral dissertation, Harvard University, Boston, MA.

Harding, S. (1995). Strong objectivity: A response to the new objectivity question. Synthese, 104, 331-349.

Harroway, D. (1988). Situated knowledges: The science question in feminism and the privilege of partial perspectives. Feminist Studies, 14(3), 575-599.

Heifetz, R. (1998). Leadership without easy answers. Cambridge: Harvard University Press. Heifetz, R., Grashow, A. \& Linsky, M. (2009). The practice of adaptive leadership: Tools and tactics for changing your organization and the world. Cambridge: Harvard Business Press.

Howe, K. R. (2009). Isolating science from the humanities: The third dogma of educational research. Qualitative Inquiry, 15(4), 766-784.

Hviding, E. (2003). Between knowledges: Pacific studies and academic disciplines. The Contemporary Pacific, 15(1), 43-73. 
Jensen, J. L. \& Rodgers, R. (2001). Cumulating the intellectual gold of case study research. Public Administration Review, 61(2), 236-246.

Johnson, L. (2006). Making her community a better place to live: Culturally responsive urban school leadership in historical perspective. Leadership and Policy in Schools, 5(1), 19-37. Johnson, L. (2007). Rethinking successful school leadership in challenging U.S. schools: Culturally responsive practices in school-community relationships. International Studies in Educational Administration, 35(3), 49-57.

Johnson, A. P. (2008). A short guide to action research. Boston, MA: Allyn and Bacon.

Kawagley, A. O. \& Barnhardt, R. (1989) Education indigenous to place: Western science meets native reality. Obtained from ERIC; available at http://www.ankn.uaf.edu/EIP.html Kawai'ae‘a, K. \& Wilson, W.H. (2007). I Kumu; I Lala: “Let there be sources; let there be branches": Teacher education in the College of Hawaiian Language. Journal of American Indian Education, 46(3), 38-55.

Kirkness, V. J. \& Barnhardt, R. (2001) First Nations and higher education. Alaska Native Knowledge Network. Available at http://www.ankn.uaf.edu/IEW/winhec/FourRs2ndEd.html

Ladson-Billings, G. (1994). The dreamkeepers: Successful teachers of African American children. San Francisco: Jossey-Bass.

Ladson-Billings, G. (1995). But that's just good teaching! The case for culturally relevant pedagogy. Theory into practice, 34(3), 159-165. 
Ladson-Billings, G. (2006). From the achievement gap to the education debt: Understanding achievement in U.S. schools. Educational Researcher, 35(7), 3-12.

Loseke, D. R. (2007). The study of cultural, institutional, organizational, and personal narratives: Theoretical and empirical integrations. The Sociological Quarterly, (48), 661-688.

Lyman, L. L., Strachan, J. \& Lazaridou, A. (2012). Reshaping social justice leadership. New York: Rowman \& Littlefield.

Lyotard, J-F. (1984). The postmodern condition: A report on knowledge. Minneapolis: University of Minnesota Press.

Meller, N. (1992). Policy control: Institutionalized centralization in the fiftieth state. In Smith, Z. and Pratt, R. (Eds.) Politics and public policy in Hawaii (11-18). Albany, NY: State University of New York Press.

Merriam, S. B. (2001). Qualitative research and case study applications in education. San Francisco: Jossey-Bass.

Meriam, L., Brown, R., Cloud, H., Dale, E., Duke, E., Edwards, H., et al. (1928) The problem of Indian administration: Report of a survey made at the request of the Honorable Hubert Wrok, Sectretary of the Interior, and submitted to him, February $21^{\text {st }}, 1928$. Baltimore: The Brookings Institute.

Meyer, M. A. (2001). Our own liberation: Reflections on Hawaiian epistemology. The Contemporary Pacific, 13(1), 124-148. 
Meyer, M. A. (2005). Remembering our future: Higher education quality assurance and indigenous epistemology. World Indigenous Nations Higher Education Consortium. Retrieved March 11, 2010 from http://www.winhec.org/docs/pdfs/Journal/Manulani\%20Meyer.pdf

Miles, M. B. \& Huberman, M. A. (1994). Qualitative analysis: An expanded sourcebook (2 ${ }^{\text {nd }}$ ed.). Thousand Oaks: Sage.

Mitchell, D.E. \& Ortiz, F.I. (2006) The evolution of educational administration knowledge. In Mitchell, D. (Ed.) New foundations for knowledge in educational administration, policy and politics. New York: Routledge.

Mitchell, D.E. (2006) Coherent knowledge and confident professional practice. In Mitchell, D.E. (Ed.) New foundations for knowledge in educational administration, policy and politics. New York: Routledge.

National Research Council. (2002). Scientific research in education. Washington, DC: National Academy Press.

National Research Council. (2004). Advancing scientific research in education. Washington, DC: National Academy Press.

Native Hawaiian Education Council. (2002). Nā honua mauli ola Hawai'i guidelines for culturally healthy and responsive learning environments. Honolulu: Native Hawaiian Education Council. 
Native Hawaiian Education Council. (2015). Na honua mauli ola, second edition:

Hawaiian cultural pathways for healthy and responsive learning environments. Honolulu: Native Hawaiian Education Council.

Nieto, S. (2004). Affirming diversity: The sociopolitical context of multicultural education $\left(4^{\text {th }}\right.$ ed.). Boston: Pearson.

Office of Hawaiian Affairs. (2006) Native Hawaiian data book. Honolulu: Office of Hawaiian Affairs.

Office of Hawaiian Affairs. (2011) Native Hawaiian data book. Honolulu: Office of Hawaiian Affairs.

Patton, M. Q. (1999). Qualitative research and evaluation methods ( $3^{\text {rd }}$. ed.). Thousand Oaks, CA: Sage.

Rawlins, N. (2011). Written testimony, Senate Committee on Indian Affairs Oversight Hearing: In our way: Expanding the success of native language and culture-based education.

Riehl, C. (2000). The principal's role in creating inclusive schools for diverse learners: A review of normative, empirical, and critical literature on the practice of educational administration. Review of Educational Research, 70(1), 55-81.

Riehl, C., Larson, C. L., Short, P. M. \& Reitzug, U. C. (2000). Reconceptualizing research and scholarship in educational administration: Learning to know, knowing to do, doing to learn. Educational Administration Quarterly, 36(3), 391-427.

Rost, J. C. (1991). Leadership for the twenty-first century. Westport, CT: Praeger. 
Ryan, J. \& Keir, S. (2008). The status of large-scale assessment in the Pacific region. Washington, D.C.: U.S. Department of Education, Regional Educational Laboratory Pacific Region.

Schein, E. (2004). Organizational culture and leadership. San Francisco: Jossey-Bass.

Schon D. (1982). The reflective practitioner. New York: Basic Books.

Senge, P. M. (2006). The fifth discipline: The art and practice of the learning organization. New York: Doubleday.

Shields, C. M. (2003). Good intentions are not enough: Transformative leadership for communities of difference. Landham, MD: Scarecrow.

Shields, C. M. (2004). Dialogic leadership for social justice: Overcoming pathologies of silence. Educational Administration Quarterly, 40(1), 109-132.

Shields, C. M. (2010). Transformative leadership: Working for equity in diverse contexts. Educational Administration Quarterly, 46(4), 558-589.

Shield, C. M. (2013). Transformative leadership in education: Equitable change in an uncertain and complex world. New York: Routledge.

Simpson, L. (2004). Anticolonial strategies for the recovery and maintenance of indigenous knowledge. American Indian Quarterly, 28(3-4), 373-384.

Smith, L. T. (1999). Decolonizing methodologies: Research and Indigenous peoples. London: Zed Books.

Spring, J. (2006). Deculturalization and the struggle for equality: A brief history of the education of dominated cultures in the United States. New York: McGraw-Hill. 
State of Hawaii Department of Education. (2008). Superintendent's $19^{\text {th }}$ annual report.

Honolulu: State of Hawaii Department of Education.

State of Hawaii Department of Education. (2009). Superintendent's $20^{\text {th }}$ annual report.

Honolulu: State of Hawaii Department of Education.

State of Hawaii Department of Education. (2010). Superintendent's $21^{\text {st }}$ annual report. Honolulu: State of Hawaii Department of Education.

State of Hawaii Department of Education. (2015). Superintendent's $21^{\text {st }}$ annual report. Honolulu: State of Hawaii Department of Education.

Taylor, F. W. (1911). The principles of scientific management. New York: Harper.

Thaman, K. H. (2003). Decolonizing Pacific studies: Indigenous perspectives, knowledge, and wisdom in higher education. The Contemporary Pacific, 15(1), 1-17.

Tierney, W. G. (1989). Curricular landscapes, democratic vistas: Transformative leadership in higher education. New York: Praeger

U.S. Congress. (2008). U.S. Code: Title 20: Section 7512 (The Native Hawaiian Education Act). Washington D.C.: U.S. Government printing office.

U.S. Congress. (2011a). A bill to amend the Elementary and Secondary Education Act of 1965 (Elementary and Secondary Education Reauthorization Act of 2011). Washington D.C.: U.S. Government printing office.

U.S. Congress. (2011b). A bill to improve Indian education, and for other purposes [The native culture, language and access for success in schools (CLASS) act]. Washington D.C.: U.S. Government printing office. 
U.S. Government Accountability Office. (2008). Native Hawaiian Education Act: Greater oversight would increase accountability and enable targeting of funds to areas with greatest need. Washington, DC: U. S. Government Accountability Office.

Villegas, A. M. \& Lucas, T. (2002). Educating culturally responsive teachers: A coherent approach. Albany: State University of New York Press.

Weber, E. (2007). Globalization, "glocal" development, and teachers' work: A research agenda. Review of Educational Research, 77(3), 279-309.

Weber, M. (1947). The theory of social and economic organization. New York: Free Press.

Wheatley, M. (2000). Leadership and the new science. San Francisco: Berret-Koehler.

Whyte, W. F. (Ed.) (1991). Participatory action research. Newbury Park, CA: Sage.

Wiseman, A. W. (2010). The uses of evidence for educational policymaking: Global contexts and international trends. Review of Research in Education, 34(1), 1-24

Yin, R. K. (2003). Case study research ( $3^{\text {rd }}$ ed.). Thousand Oaks, CA: Sage. 
APPENDIX A:

LETTER OF RECRUITMENT

Aloha!

Mahalo nui loa for allowing me to introduce myself and explain my research interests to you. My name is Bert Klunder, and I currently live and work in East Hawai'i. I am a doctoral student conducting dissertation research for a Higher Education Administration Ph.D. program through Illinois State University. The topic of my dissertation is culturally responsive educational leadership (CREL), and I will be conducting a qualitative case study focused on Native Hawaiian education innovations exemplifying this type of leadership - specifically, the first and forthcoming Pathways editions of the Na Honua Mauli Ola Guidelines for Culturally Healthy and Responsive Learning Environments and the Kumu Honua Mauli Ola Philosophy Statement.

The core purpose of my research is to gain a more complete understanding, from a nonIndigenous perspective, of how these Native Hawaiian education innovations (and, more importantly, how the processes through which they were developed) exemplify CREL and how they can inform and guide educators elsewhere in the American system and abroad who are engaged in resonant efforts to address persistent issues of equity in education. In addition to documenting participants' stories of how innovations like NHMO and KHMO were developed and implemented through this research, I also seek to encourage wider awareness of the Native Hawaiian Education Movement, including its history, progress and continuing evolution. NHMO and $K H M O$ represent the culmination of years of collective effort within the Movement, and serve as illuminating examples of local Indigenous innovations, both in product and in process.

As a witness to your important achievements, and in an effort to contribute to the ongoing progress of local innovations, I am focusing my research on the work you and others have undertaken to advance CREL in the singularly unique Hawaiian context. I humbly seek your blessing in this research effort and I invite you to participate in this study as an interviewee. While NHMO and KHMO speak for themselves as exemplary products, the all-important stories of the processes through which they were developed can only come from those who created them. In this way, the most important data I seek to collect in my research will come directly from those who are willing to share their views, opinions and experiences concerning the journey that led to today through brief individual interviews - which will be private and confidential. This research will guide the remaining phases of my dissertation fieldwork, which will explore related innovations and the wider Movement as a whole. I am happy to address any questions or concerns you have related to this research, and I can't thank you enough for allowing me to share this with you. If you are interested in contributing your views and voice to my study, please let me know individually at any point and we can discuss how to proceed.

Sincerely, 
Bert Klunder

P.O. Box XXXXXXX

Kea'au, HI XXXXX

Cell: $X X X-X X X-X X X X$

Email: xxxxxxx@ilstu.edu or xxxxxxx@gmail.com 
APPENDIX B:

LETTER OF CONSENT

Dear Interviewee:

I am a graduate student under the direction of Dr. Mohamed Nur-Awaleh in the College of Education at Illinois State University. I am conducting a research project concerning the topic of culturally responsive educational leadership (CREL) and involving a qualitative case study of Native Hawaiian education innovations. Interviews will be conducted with members of the writing committees who co-authored the first and/or second editions of the Na Honua Mauli Ola Guidelines for Culturally Healthy and Responsive Learning Environments and/or the Kumu Honua Mauli Ola Philosophy Statement in an effort to identify salient features, core elements and key aspects of CREL represented in these products and in the processes through which they were developed. The core purpose of this research (beyond documenting participant accounts of how locally developed CREL innovations were developed and implemented) is to understand more completely, from a non-Indigenous perspective, how these innovations can offer meaningful insight and guidance for education professionals elsewhere who are engaged in leadership efforts to address persistent issues of equity in education.

Receipt of this letter acknowledges that you have agreed to participate in this study, which will involve a three-phase interview process. The first phase will entail a typed survey, submitted electronically, asking you to respond to general questions about CREL and Native Hawaiian education related to your experiences. The second and third phases will each entail a 30-60 minute interview conducted face-to-face in a private room. During the second phase interview, you will be asked to tell the stories of how KHMO and/or NHMO innovations were developed and implemented, along with the story of the wider Native Hawaiian education movement, from your perspective. The third interview phase will entail a semi-structured list of questions pertaining to the study topic of CREL, the Native Hawaiian education movement and KHMO/NHMO innovations. Face-to-face interviews will be audio recorded (to ensure accuracy of transcriptions), and receipt of this letter also acknowledges that you have granted permission to record these interviews.

Your participation in this study is completely voluntary. You are not expected to discuss any emotionally sensitive material that will make you feel uncomfortable in any way, and this constitutes the risk involved in this study, which I will make every effort to minimize as the interviewer. If you choose not to participate or to withdraw from the study at any time, there will be no penalty of any kind. The results of this study may be published, but your name will not be used. I will take all precautions to maintain your confidentiality, and will keep all documentation of your participation securely stored under lock and key. Pseudonyms will be used in both the transcriptions of the interview and in the final report. The information 
provided will not be used in any way to affect your professional reputation or influence the assessment of your performance in any position you may be involved in now or in the future.

While it is hoped that you will benefit from the opportunity to have your views and opinions heard concerning your experiences in Native Hawaiian education, there may be no other direct benefit to you as a result of your participation. A possible benefit of your participation is to help educators locally and abroad learn from your testimony concerning CREL and your experiences in relation to their work.

If you have any questions concerning this research study, please call me at (XXX) XXX-XXXX or contact Dr. Mohamed Nur-Awaleh at (XXX) XXX-XXXX.

Thank you very much for your willingness to participate in this research study.

Sincerely,

\section{Bert Klunder}

If you have any questions about your rights as a subject/participant in this research, or if you feel you have been placed at risk, you can contact the Research Ethics \& Compliance Office at Illinois State University at (XXX) XXX-XXXX and/or XXXXX@ilstu.edu. 


\section{APPENDIX C: \\ PARTICIPANT SURVEY}

Mahalo nui loa for completing this survey. Please type your responses in the space below each item, and feel free to create more space as needed. Your responses will be kept confidential.

1. How have you been connected with Native Hawaiian education personally and professionally throughout your life?

Please describe the nature and timeline of all your roles related to Native Hawaiian education. 
2. Please explain your involvement in the development and/or implementation of the following:

- Kumu Honua Mauli Ola: A Native Hawaiian Education Educational Philosophy Statement $(1999,2009)$

- Na Honua Mauli Ola Guidelines for Culturally Healthy and Responsive Learning Environments ( $1^{\text {st }}$ edition, 2002)

- Na Honua Mauli Ola Cultural Pathways for Culturally Healthy and Responsive Learning Environments ( $2^{\text {nd }}$ edition, forthcoming) 
3. Please explain what was most meaningful about your experiences developing and/or implementing these innovations.

4. Please summarize your involvement as a whole in the Native Hawaiian Education Movement. 
5. Please explain what culturally responsive educational leadership means to you.

6. Please explain what you think is most meaningful (and why you think this) about $K H M O$ and NHMO innovations in relation to culturally responsive educational leadership efforts in Hawai' $i$. 


\section{APPENDIX D: \\ PARTICIPANT ACCOUNTS OF RELEVANT EXPERIENCES}

- Prompts:

1. Tell the story of the Native Hawaiian Education Movement, from your perspective.

2. Tell the story of the Kumu Honua Mauli Ola Philosophy Statement, the Na Honua Mauli Ola Guidelines and the Na Honua Mauli Ola Pathways, from your perspective.

3. What do you consider to be the most important takeaways from these stories?

- Review responses from Phase 1 Survey

- Probes:

1. Describe key experiences developing and/or implementing KHMO and $N H M O$ innovations that you think exemplify culturally responsive educational leadership.

2. Recount examples of significant moments and powerful experiences in your life, work and learning that you think reflect the essence of $K H M O, N H M O$ and related innovations.

3. Explain what you think is most important about the impact you have witnessed $K H M O$ and NHMO innovations having in Hawai'i and for the Native Hawaiian Education Movement. 


\section{APPENDIX E:}

\section{SEMI-STRUCTURED INTERVIEW QUESTIONS}

1. Please define "culturally responsive educational leadership" in your own words.

2. Explain what you think is most important to understand about culturally responsive educational leadership in the Hawaiian context.

3. Following your explanations thus far, what aspects of culturally responsive educational leadership do you think are unique to the Hawai'i circumstance and only applicable here?

4. What do you think are important aspects of culturally responsive educational leadership that could be considered "universal" and/or widely applicable in other contexts?

5. Describe examples of what you consider to be exemplary practices in culturally responsive educational leadership that are suited for the Hawaiian context.

6. Describe what you consider to be significant challenges that various types of education professionals in Hawai'i can face when striving to be culturally responsive in their work.

7. Explain how the process of developing the first and/or second edition of the NHMO Guidelines (and/or, if applicable, the KHMO Philosophy Statement) was undertaken.

8. Describe what you think were the most effective aspects of the processes through which the first and/or second editions of $\mathrm{NHMO}$ and/or $\mathrm{KHMO}$ were created.

9. Explain how you think the new Pathways edition of $N H M O$, and the processes that yielded it, can inform and guide educational leadership efforts in Hawai'i and in other contexts.

10. Explain what you think is important to understand about the evolution of NHMO and what this culminating work reflects concerning the wider Native Hawaiian Education Movement.

11. Describe other related Native Hawaiian education innovations you consider to be significant, including why you think they are significant.

12. Explain what you think are the most important priorities and issues to be addressed in order for the Native Hawaiian Education Movement to flourish. 